\title{
SPATIAL VARIATIONS OF THE INVASIBILIITY OF SLASH PINE FLATWOODS TO CHINESE TALLOW (Triadica sebifera) INVASION: MACHANISMS AND KEY FACTORS AT THE MICROSCALE
}

Fan, Shaoyang Yang, Nancy Loewenstein, Nannan Cheng, and Sunil Nepal

School of Forestry and Wildlife Sciences, Auburn University, Auburn, AL 36849 


\section{Definition of ecosystem invasibility}

- In invasion ecology, the term "invasibility" has been coined to describe the susceptibility (an intrinsic property) of recipient ecosystems to invasive species, a manifestation of the interactions of multiple processes and factors (Lonsdale 1999)

- The invasibility of an ecosystem to biological invasion is determined by its structure, local disturbance, propagule pressure level, and the biological traits of the invasive species (Davis et al. 2000).

- As for a specific invasive species such as Chinese tallowtree (Triadica sebifera), the invasibility of an ecosystem can be quantified by its community-landscape structure, propagule pressure and disturbance/stress regime (Alpert et al. 2000, Davis et al. 2000, D’Antonio et al. 2001). 


\section{The conceptual diagram of tallow invasion at the micro scale showing the filters that affect tallow invasion processes}

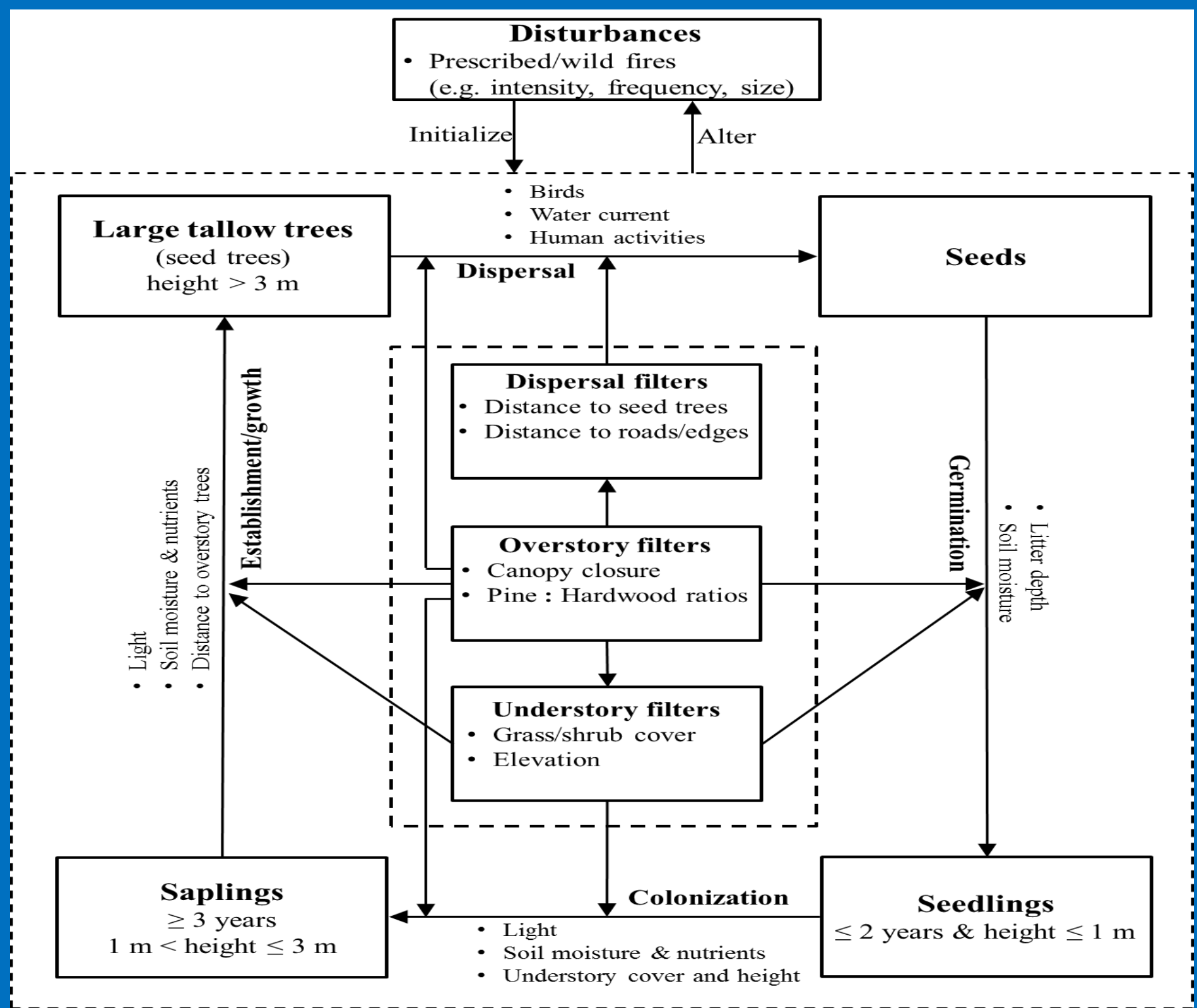




\section{A case study: Tallow tree invasion in the Grand Bay National Wildlife Refuge (GBNWR)}

GBNWR is

- A landscape of $\sim 18,000$ ac dominated by longleaf/slash pine flatwoods and savannas.

- Other ecosystems include salt marshes, maritime forest, wetlands, and bays.

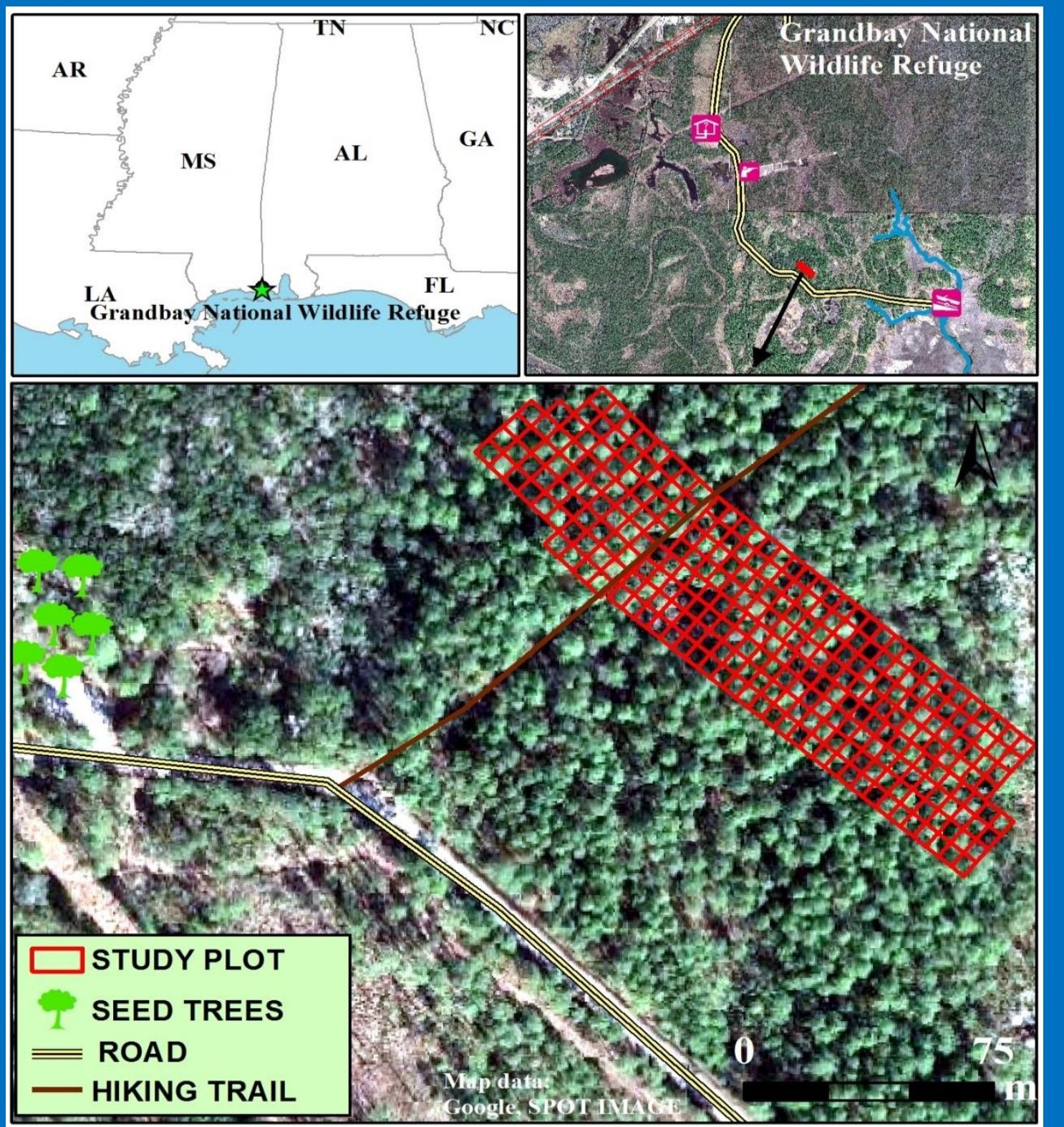




\section{Data collection/preparation}

- The plot was then divided into a grid of contiguous quadrats of $\sim 30 \mathrm{~m}^{2}$ in size $(\mathrm{n}=281)$.

- The species and dbh, if present, of all mapped trees ( $n=2,190)$ using a high-resolution GPS device were measured and recorded.

- The raster data of six filters including distance to the nearest seed trees, distance to the nearest road or the hiking trail, overstory canopy closure (\%), basal area ratio of pine to hardwoods, understory grass coverage (\%), and elevation (microtopographic condition) were generated to predict spatially-varying probability of tallow invasion by size class (trees, saplings and seedlings) 


\section{Methods}

- First, generate a multitype planar point process (PPP) to $\{Z(s), s \in D\}$ to quantify/map the spatial distribution of Chinese tallow and other native species.

- Compute the cross-type pair correlation function (pcfcross, $\mathrm{g}(\mathrm{r}))$ to examine the spatial relationship between tallow (seedlings, saplings and trees) and other overstory trees (pine and hardwoods) across different spatial scales $r$.

- Compute the nonparametic (smoothed) rhohat $(\rho(Z(s))$ function to quantify the partial effect of individual filters on local intensities of tallow trees, saplings and seedlings.

- Run the multitype point process model (relrisk.ppm) by incorporating the polynomials of all six spatial filters to predict spatial probability of tallow: $P(y, u)=\boldsymbol{X}\left(\boldsymbol{\beta}+\boldsymbol{\beta}_{y}\right)+\boldsymbol{\varepsilon}$ 


\section{Results: Spatial distribution patterns}
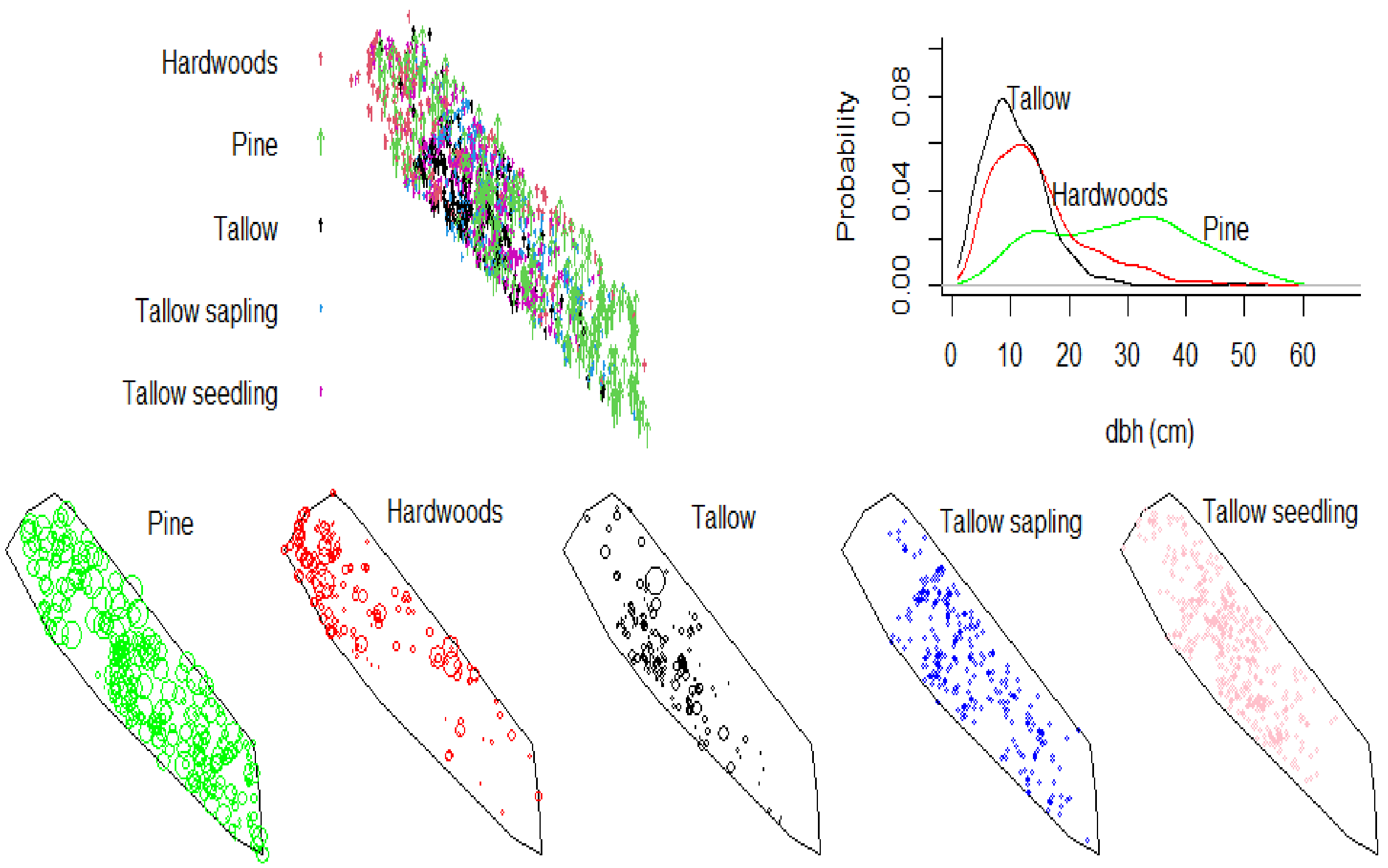


\section{Results: Spatial relationships between}

tallow and overstory pine and hardwoods

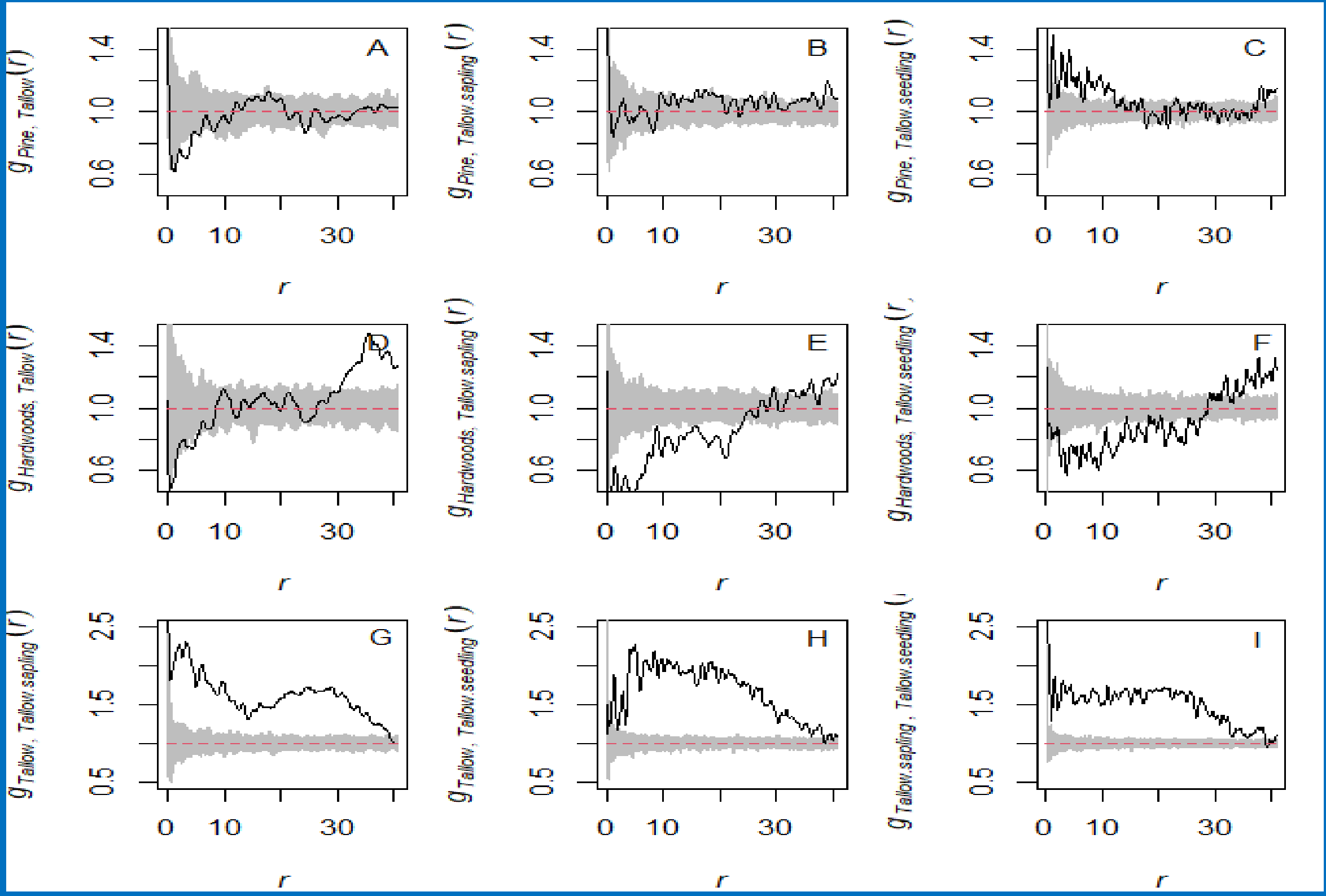


Results: Spatial heterogeneity of biotic and abiotic filters used in this study
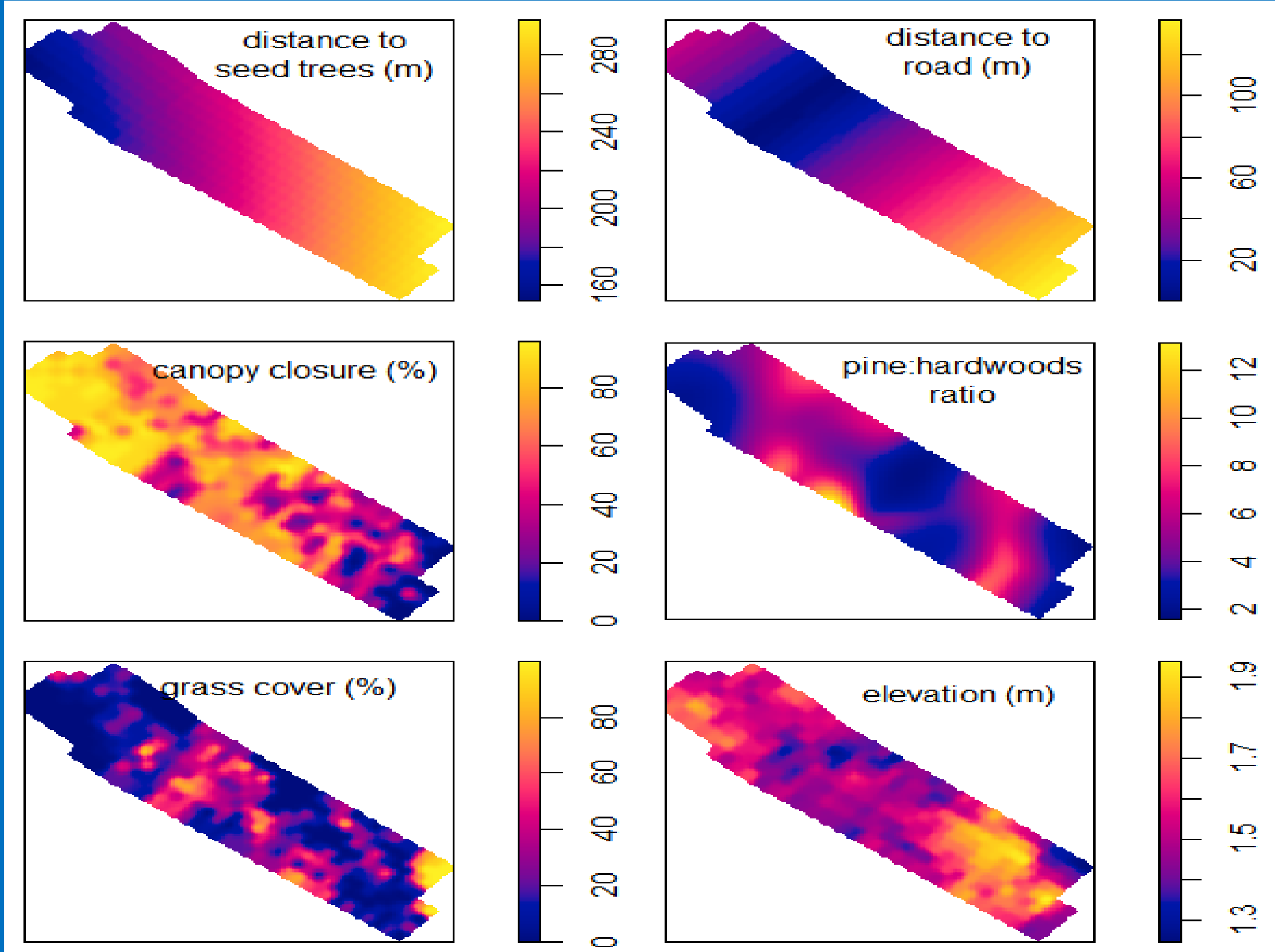
Results: Change of local densities of tallow

\section{with biotic and abiotic filters}
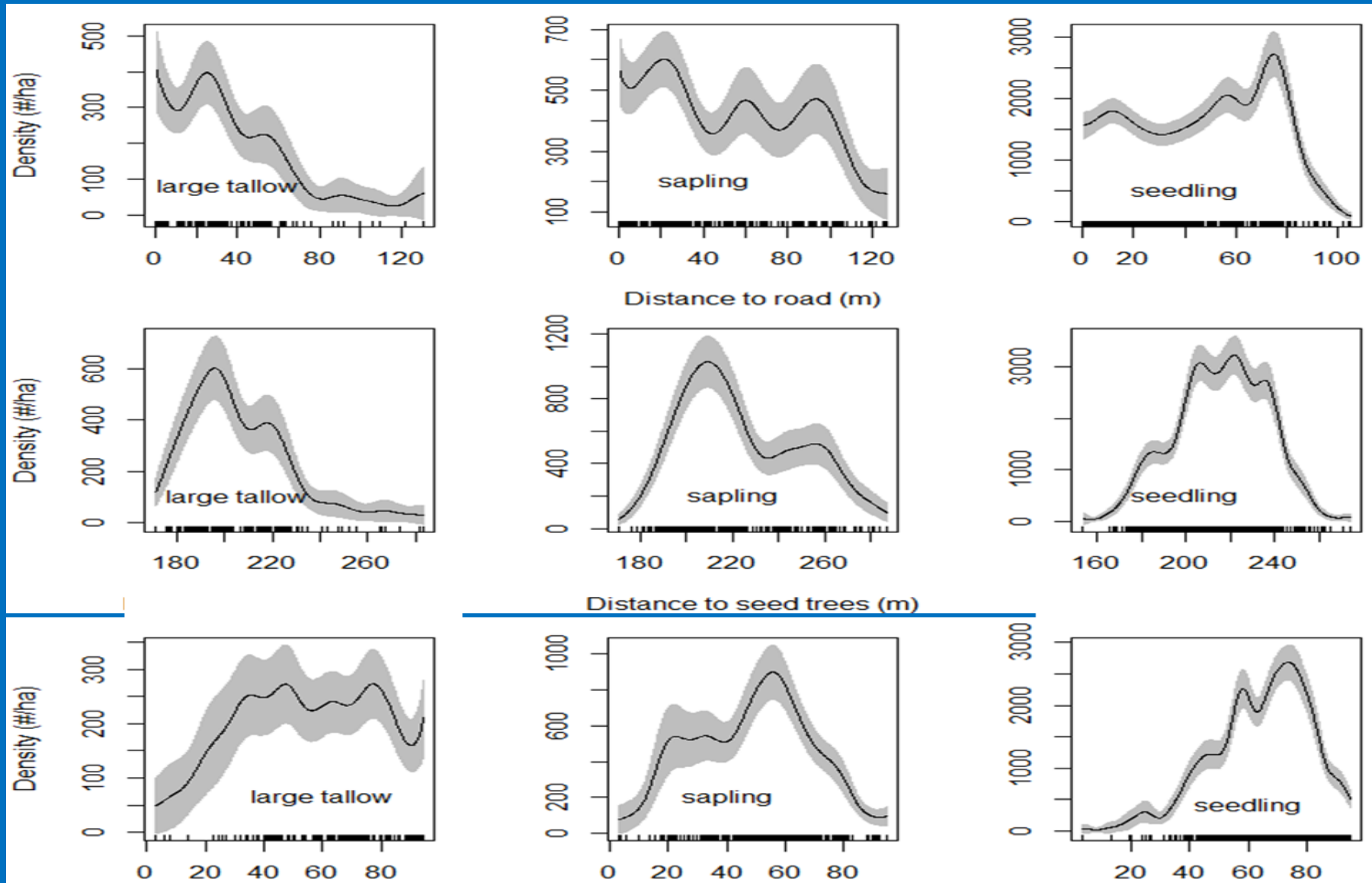

Distance to seed trees (m)
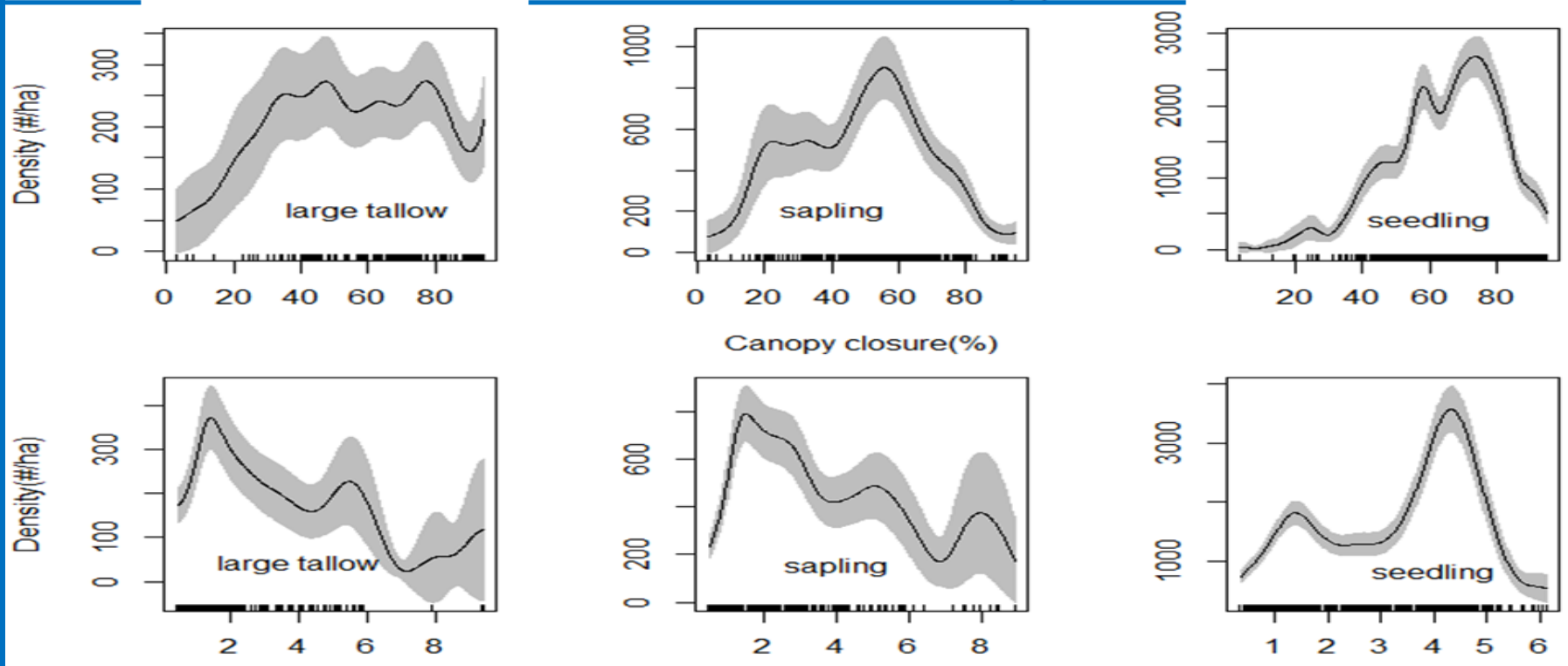

pine:hardwood ratio 
Results : Change of local densities of tallow with biotic and abiotic filters (cont.)
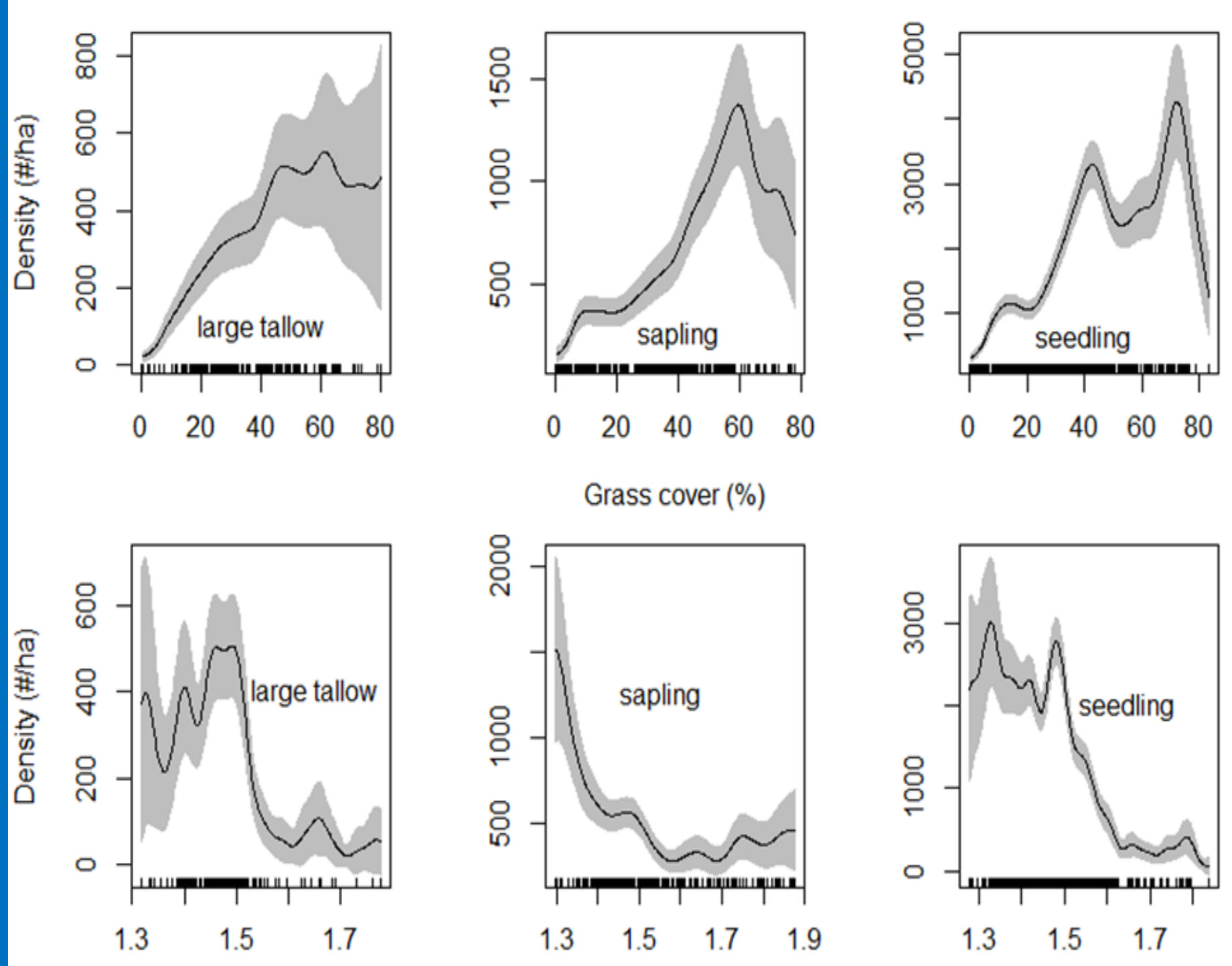

elevation (m) 


\section{Results: Model performances and diagnostics}

\section{Full model: $\mathrm{D}+\mathrm{O}+\mathrm{U}$}
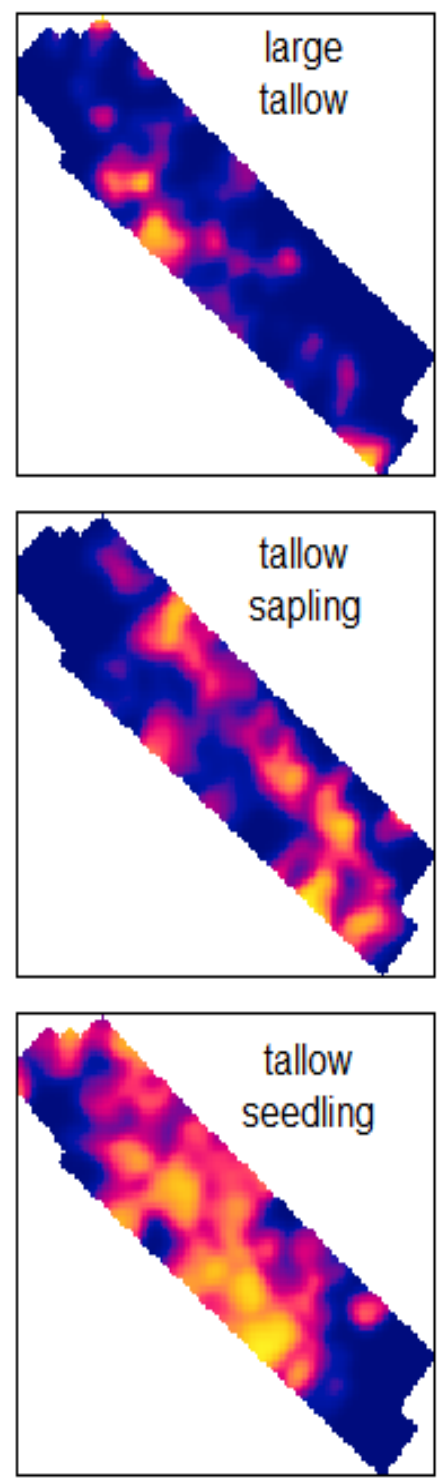
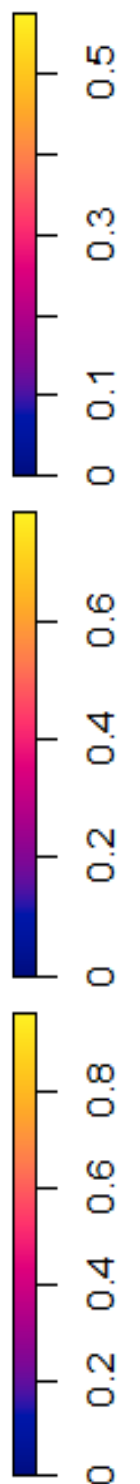
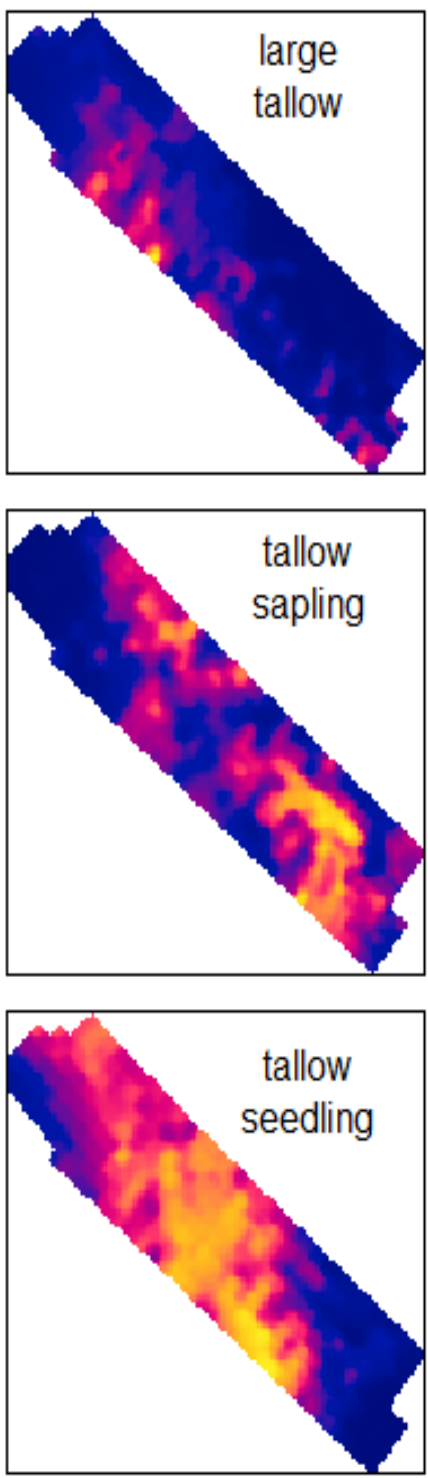

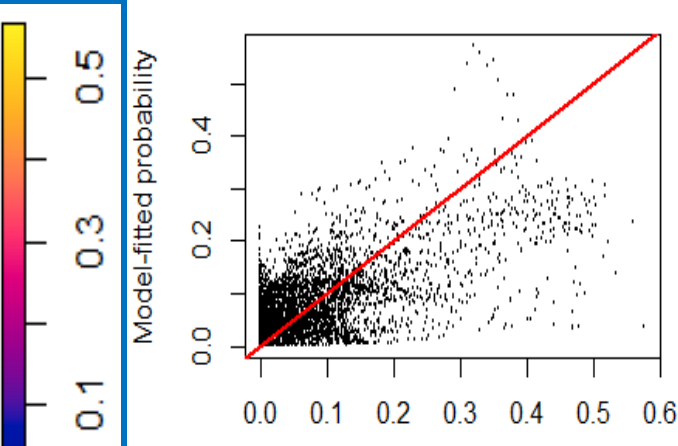

Kernel-smoothed probability
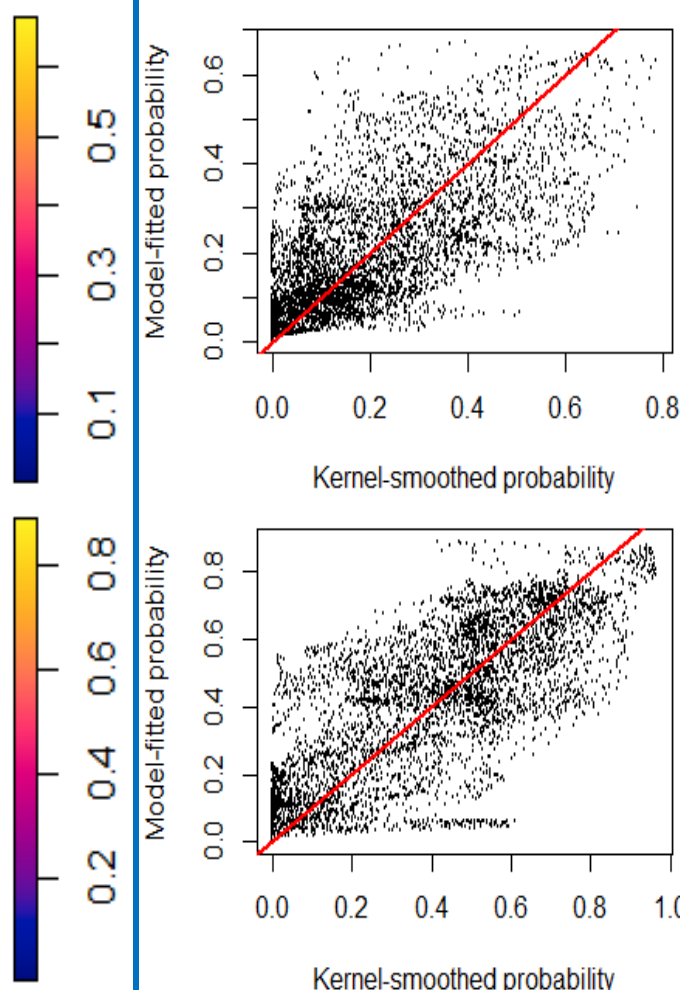

Kernel-smoothed probability

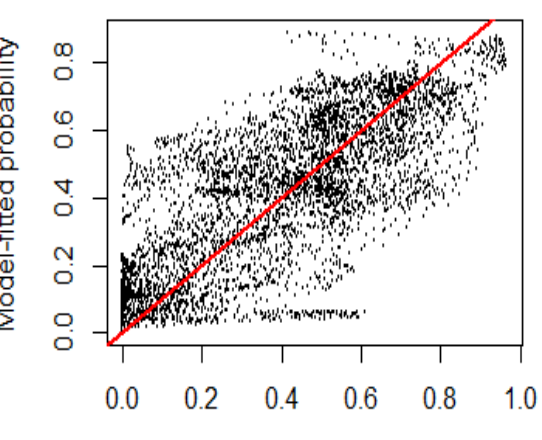

Kernel-smoothed probability
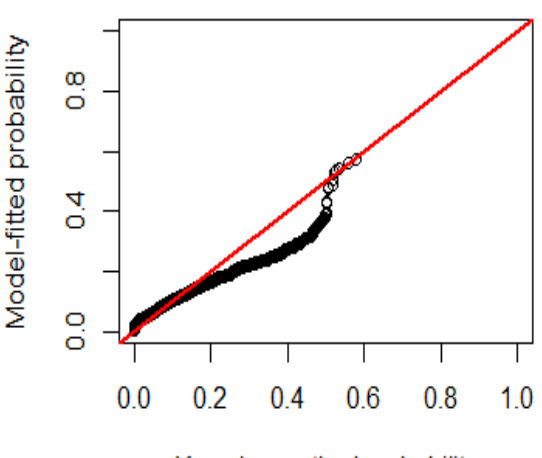

Kernel-smoothed probability

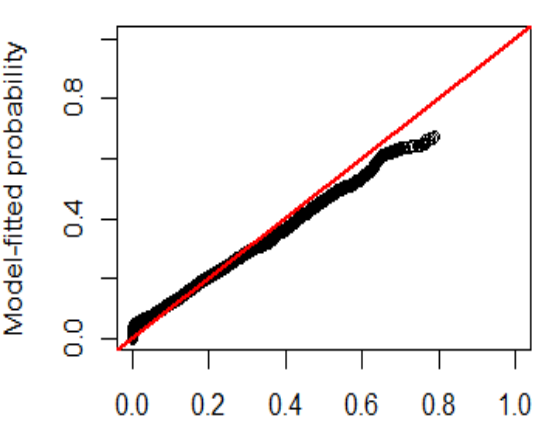

Kernel-smoothed probability

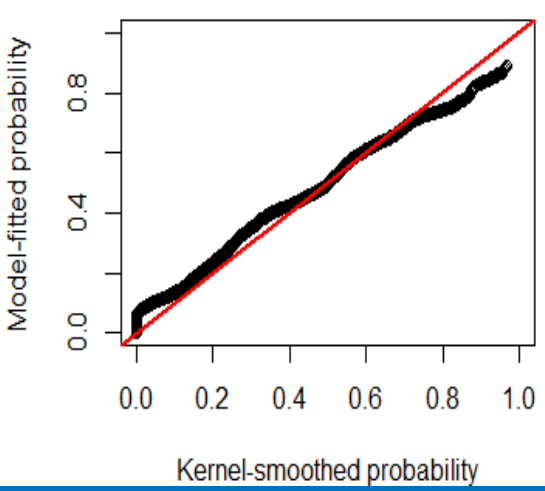




\section{Results: Model performances and diagnostics}

\section{The sub-model with dispersal filters}
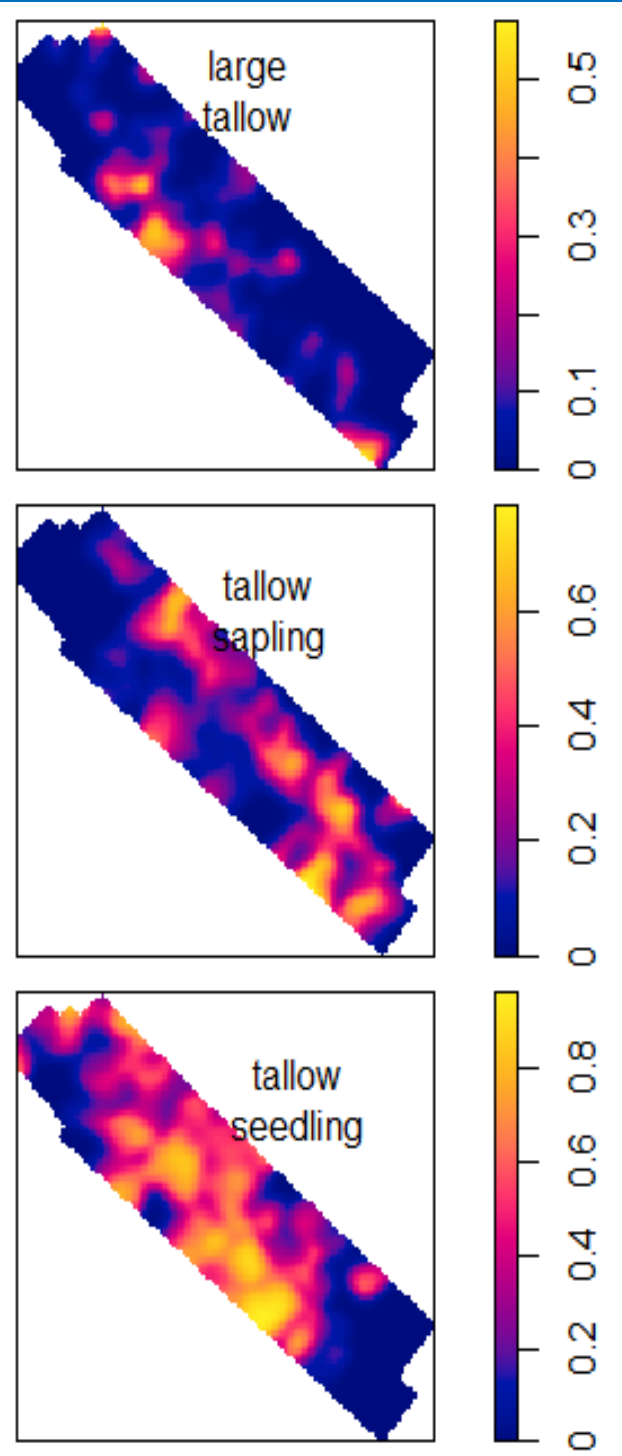
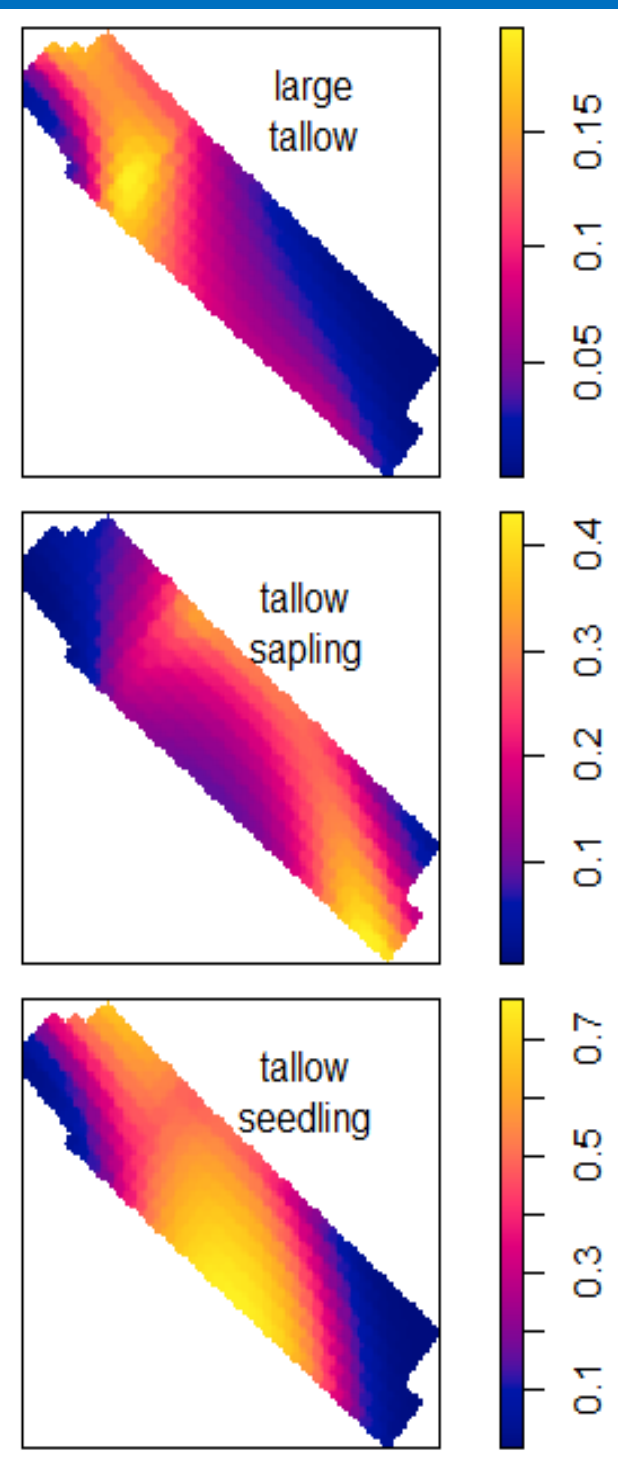
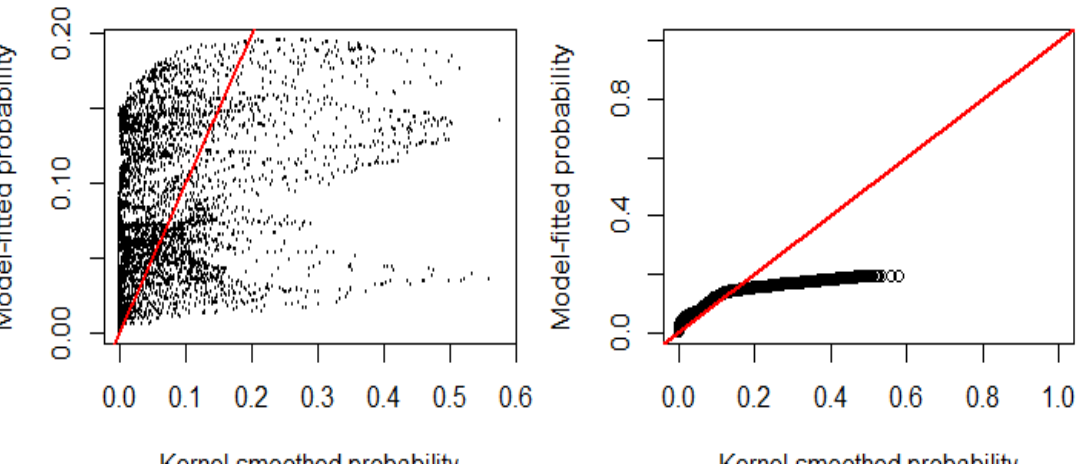

Kernel-smoothed probability
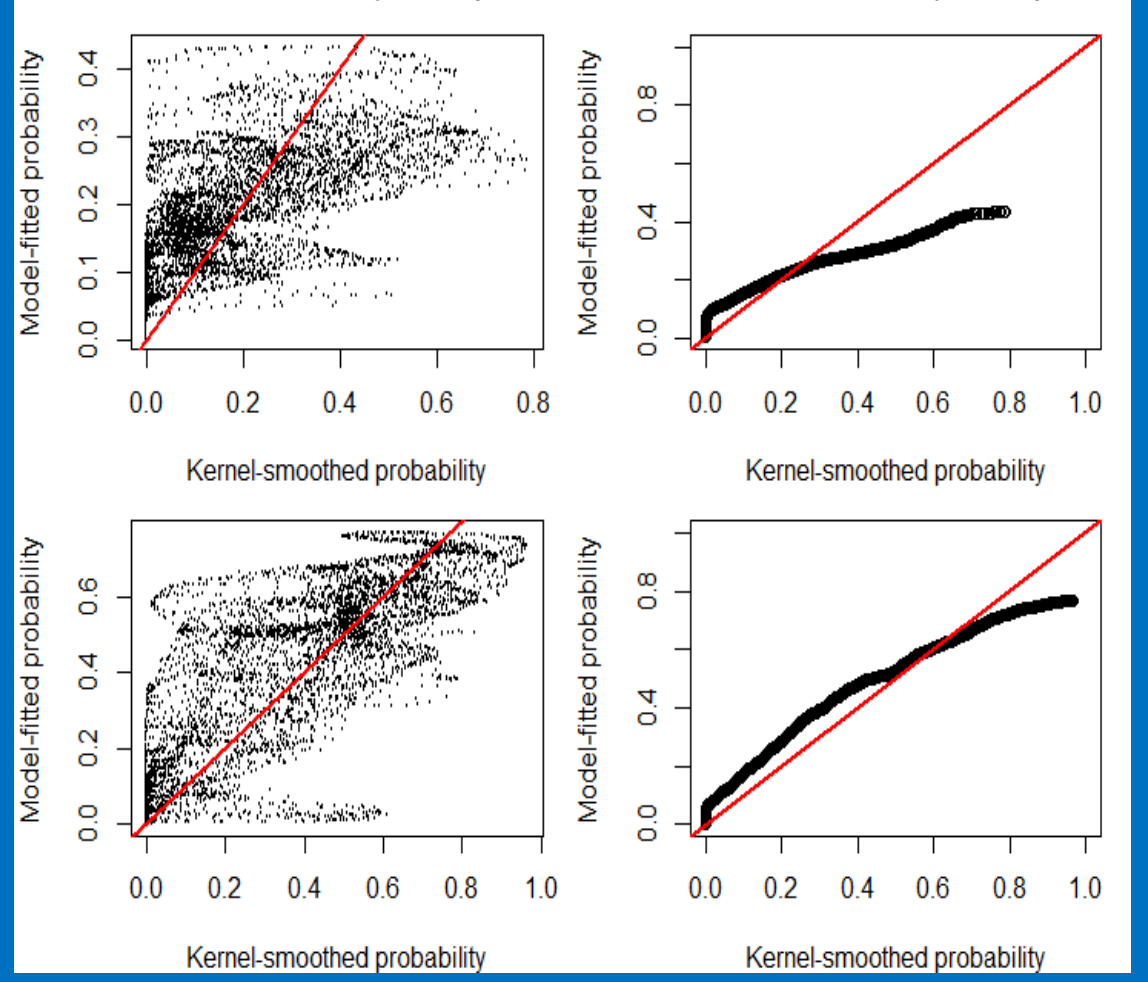


\section{Results: Model performances and diagnostics}

\section{The sub-model with overstory filters}
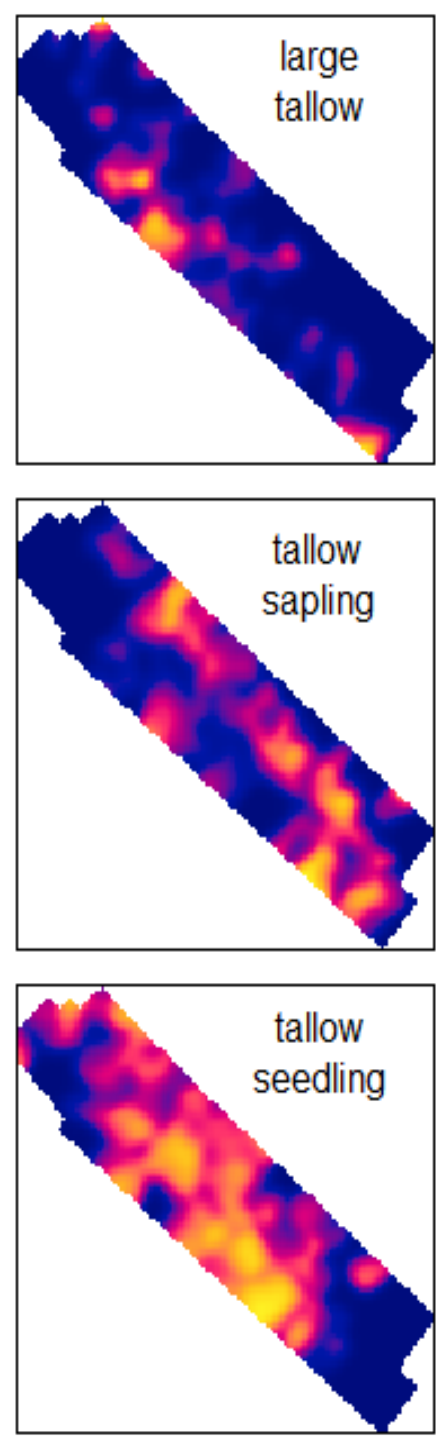
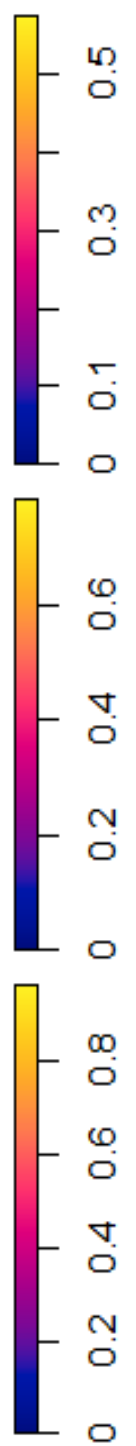
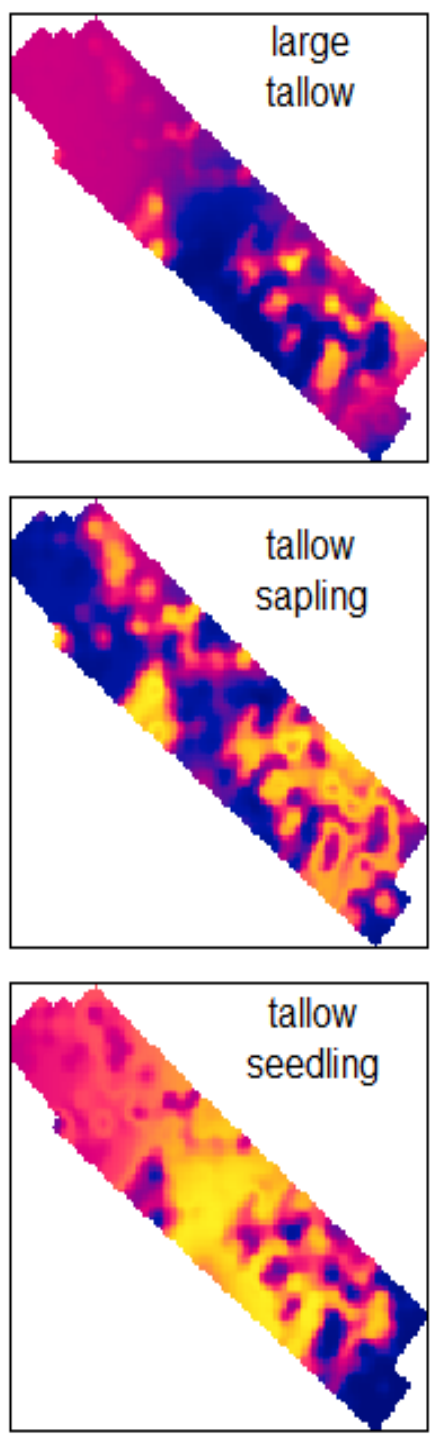
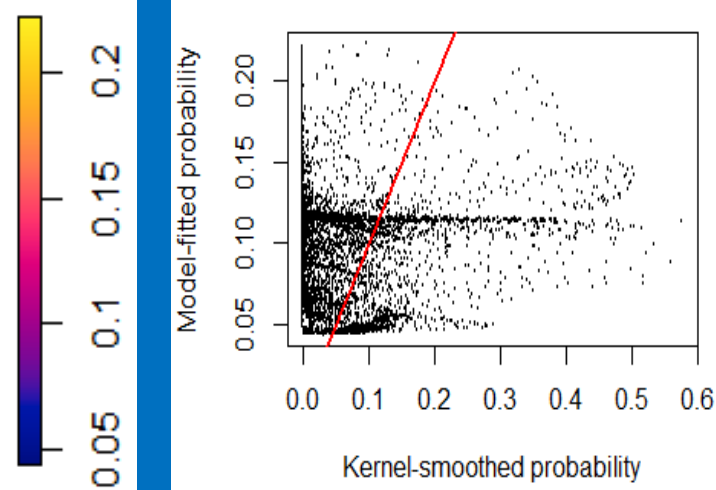

Kernel-smoothed probability
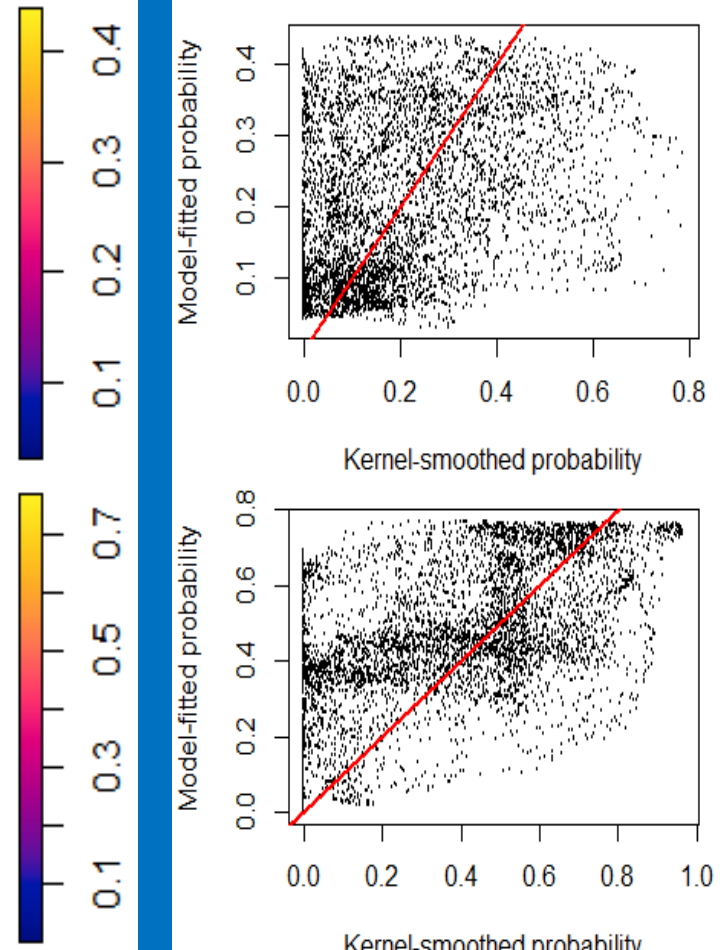

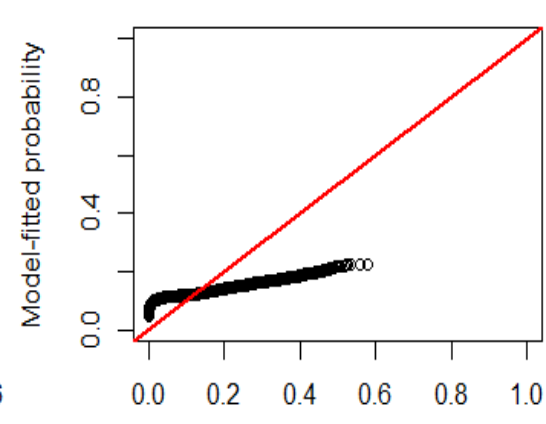

Kernel-smoothed probability

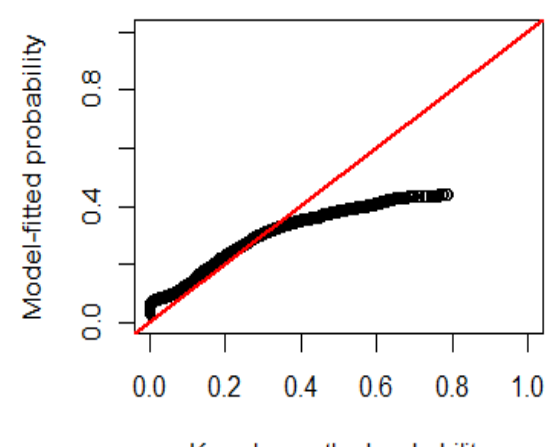

Kernel-smoothed probability

Kernel-smoothed probability

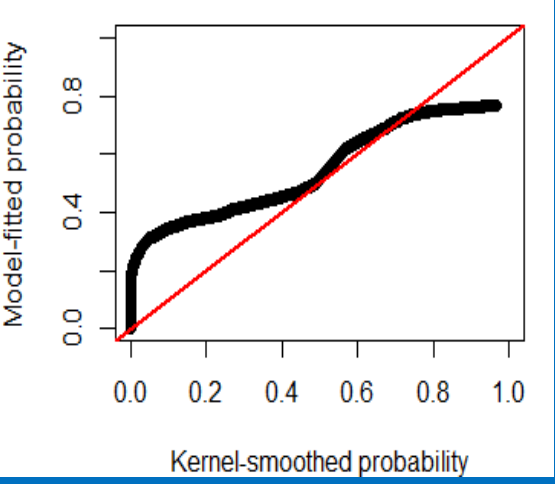




\section{Results: Model performances and diagnostics}

\section{The sub-model with understory filters}
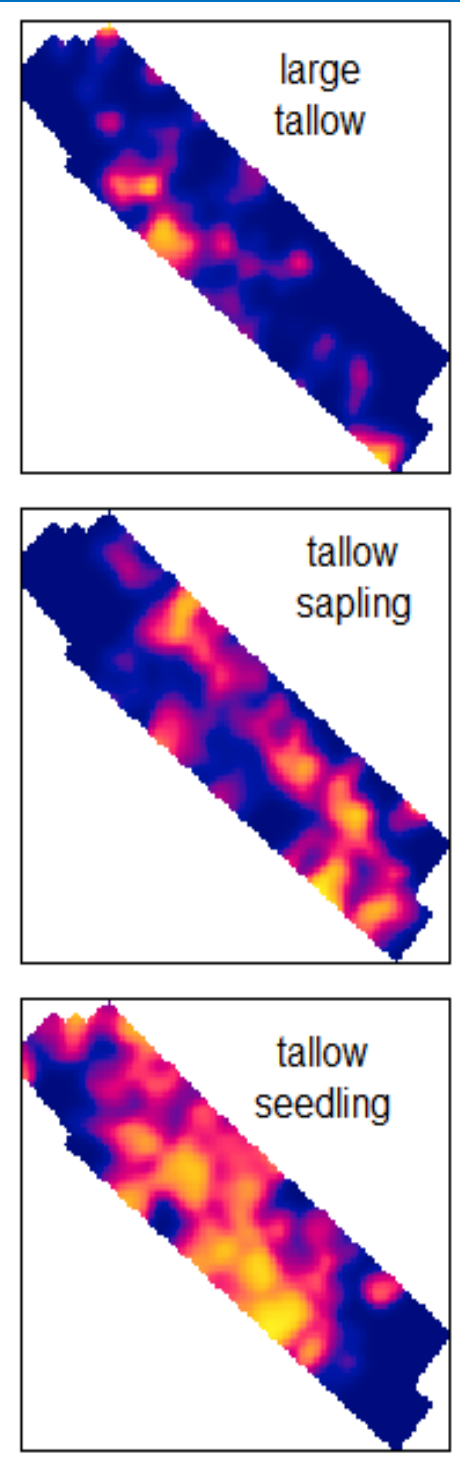
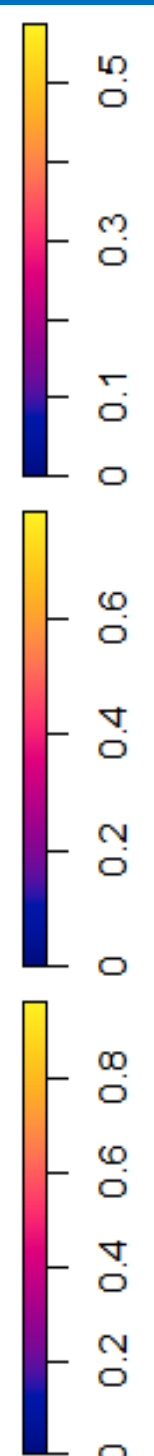
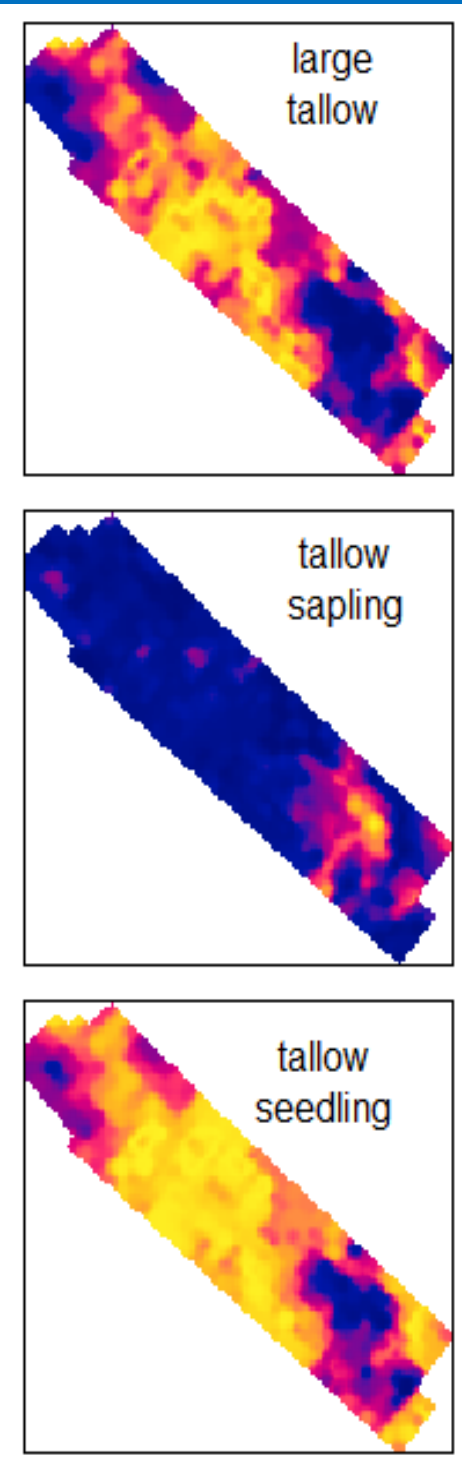
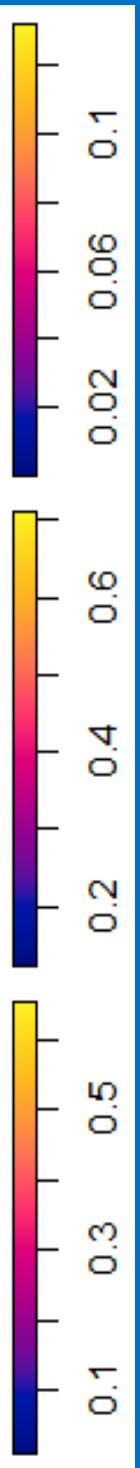
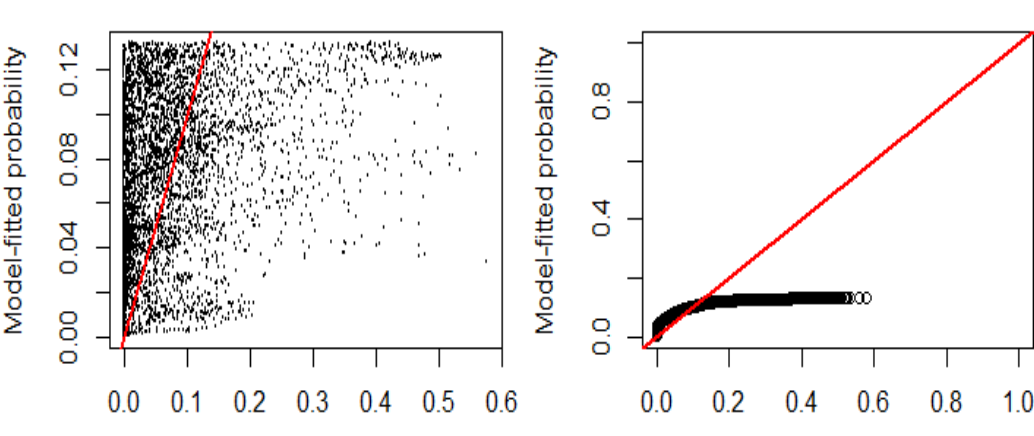

Kernel-smoothed probability

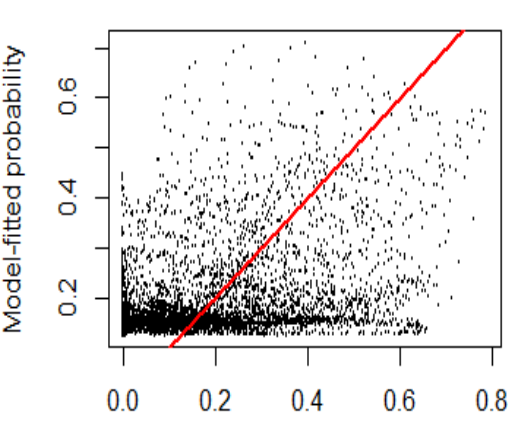

Kernel-smoothed probability

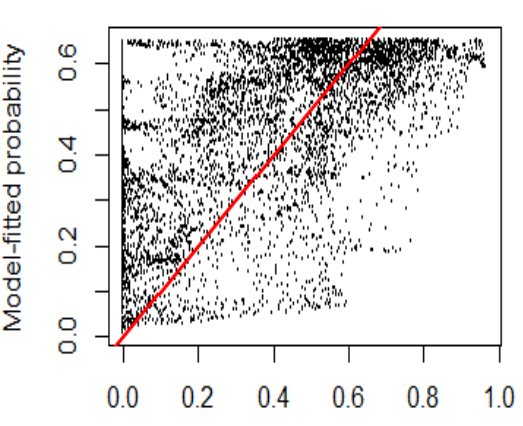

Kernel-smoothed probability
Kernel-smoothed probability

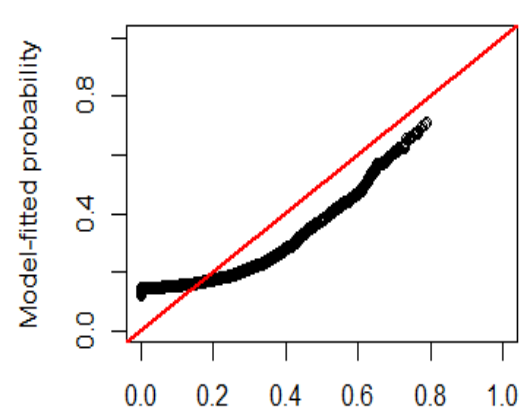

Kernel-smoothed probability

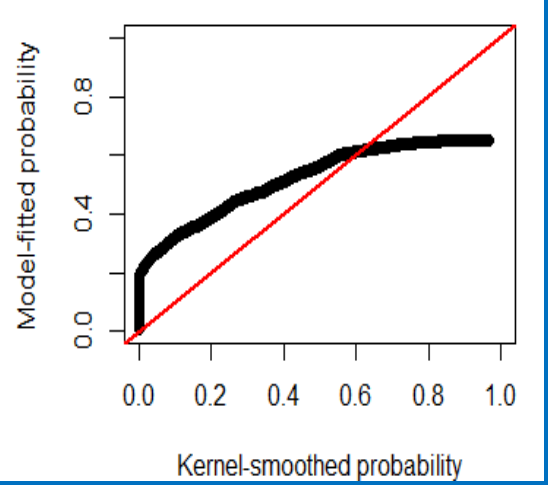




\section{Results: Model performances and diagnostics}

\section{The sub-model with dispersal + overstory filters}
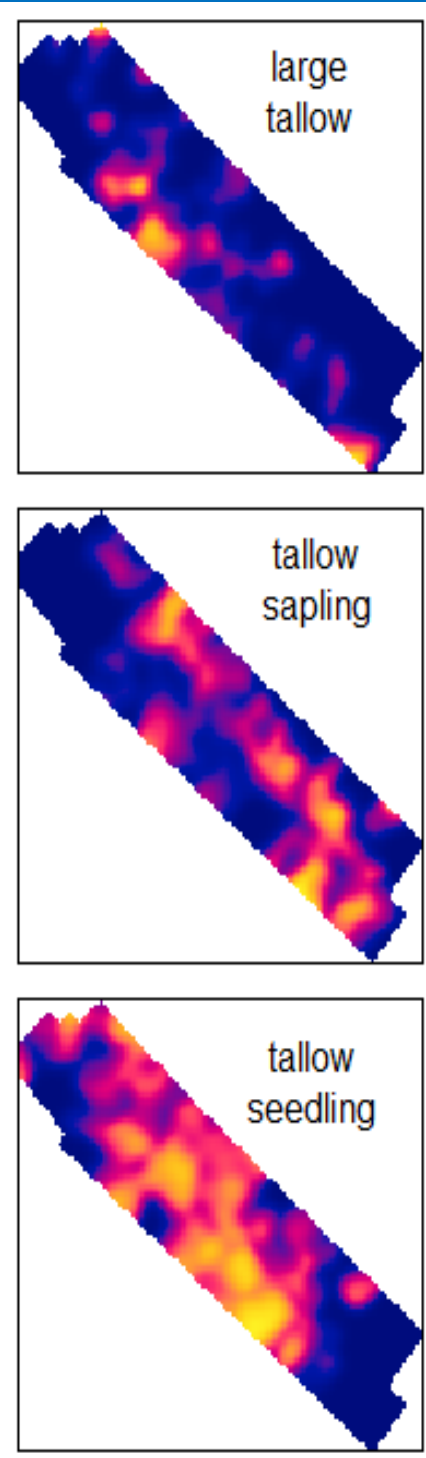
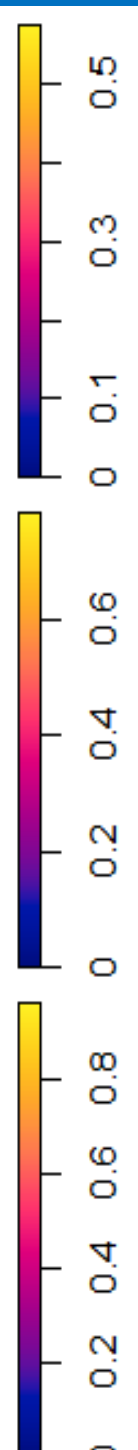
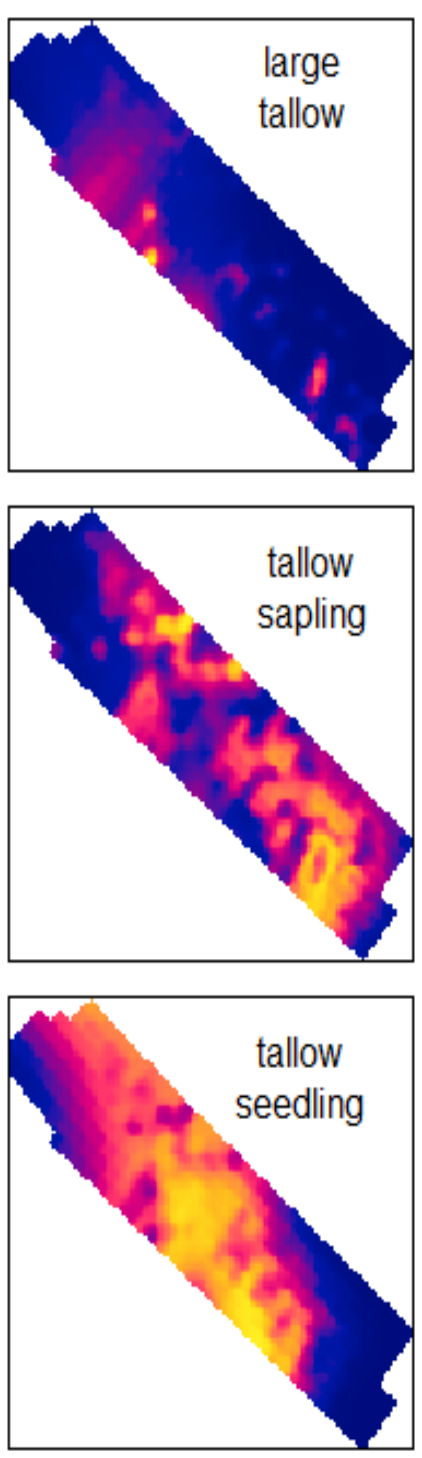
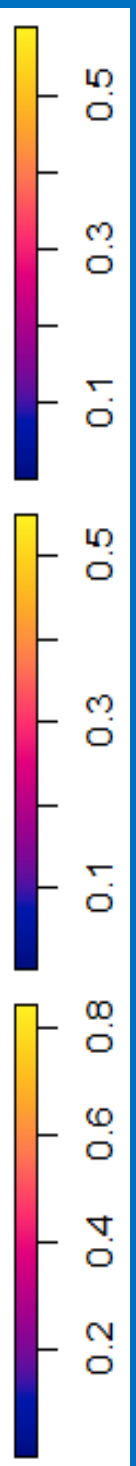

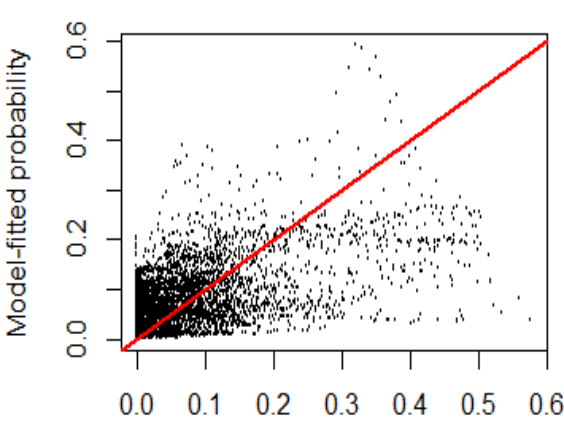

Kernel-smoothed probability

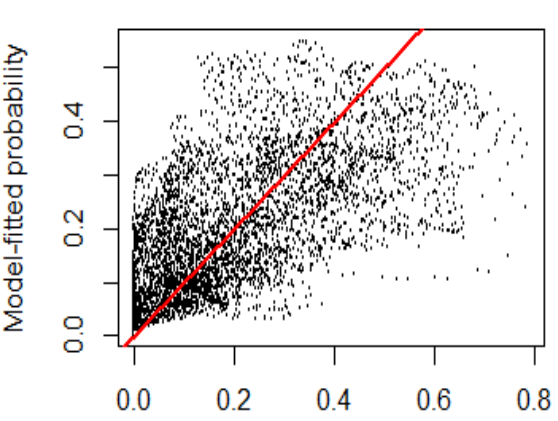

Kernel-smoothed probability

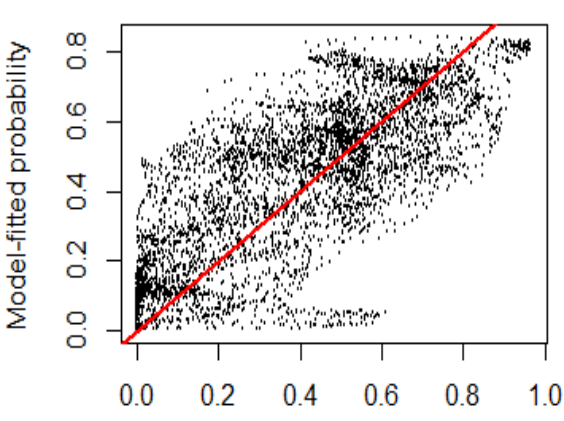

Kernel-smoothed probability

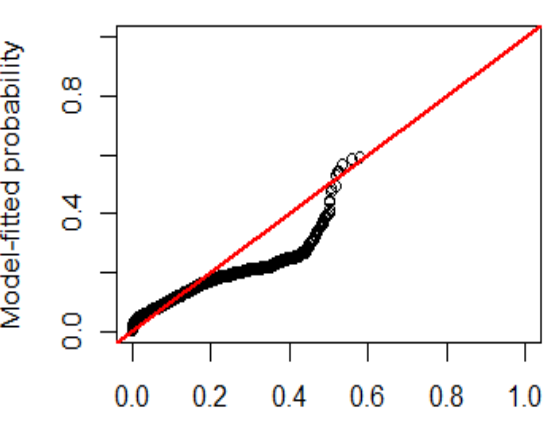

Kernel-smoothed probability

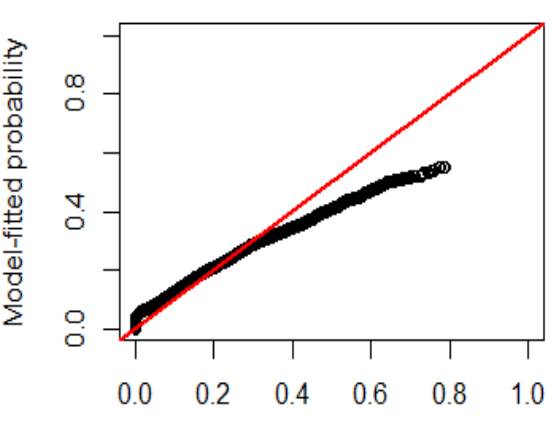

Kernel-smoothed probability

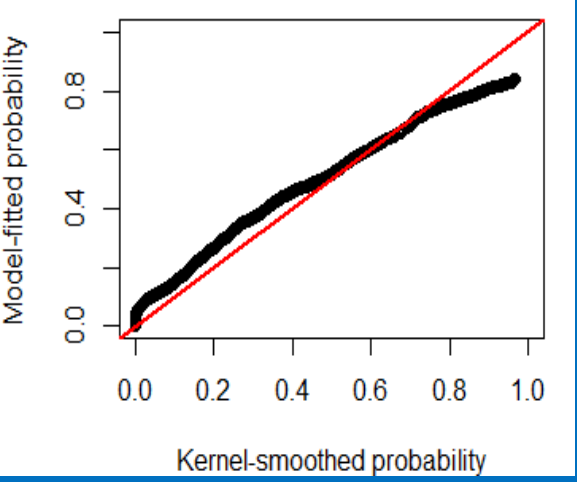




\section{Results: Model performances and diagnostics}

\section{The sub-model with dispersal + understory filters}
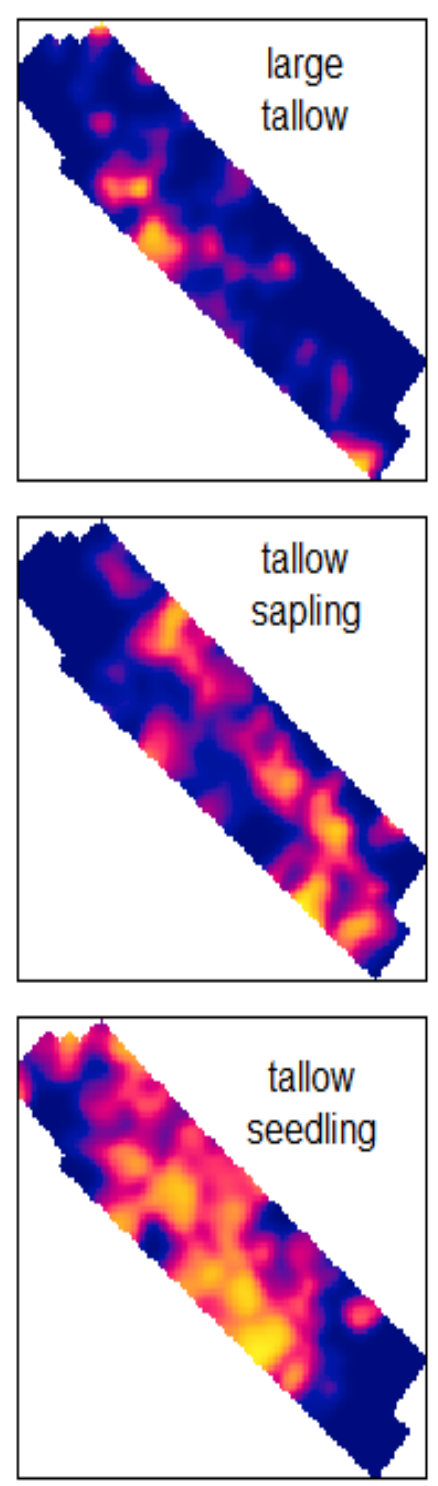
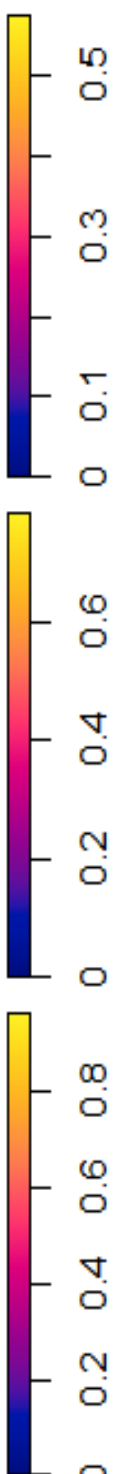
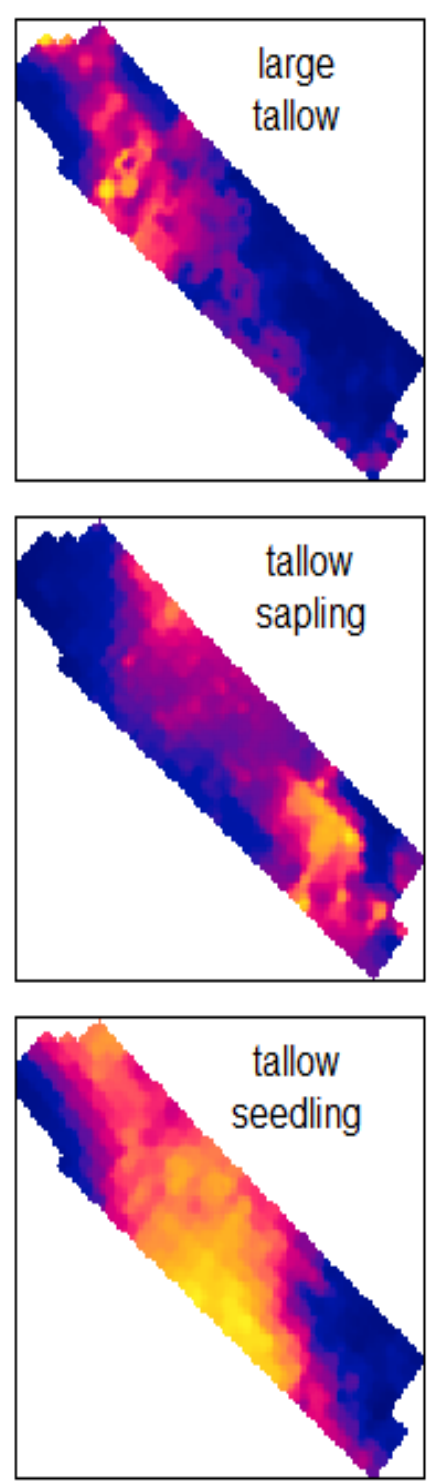
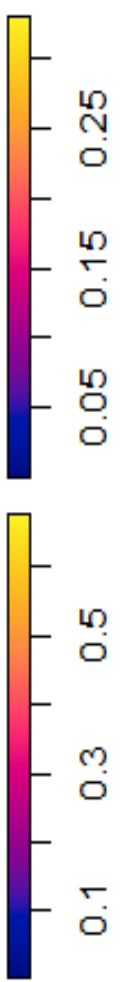

$\square+\infty$

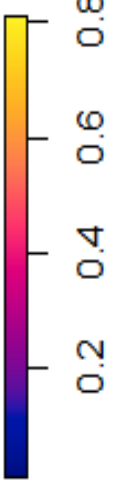

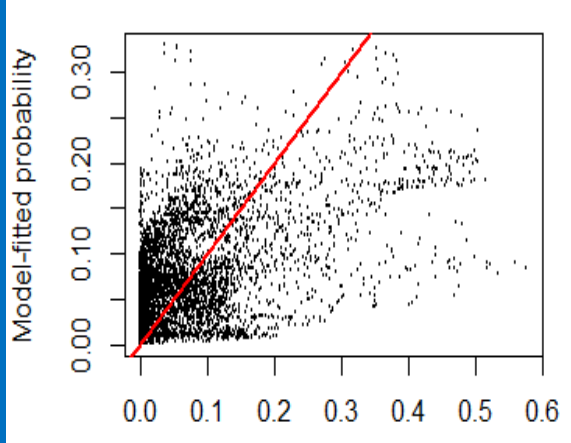

Kernel-smoothed probability
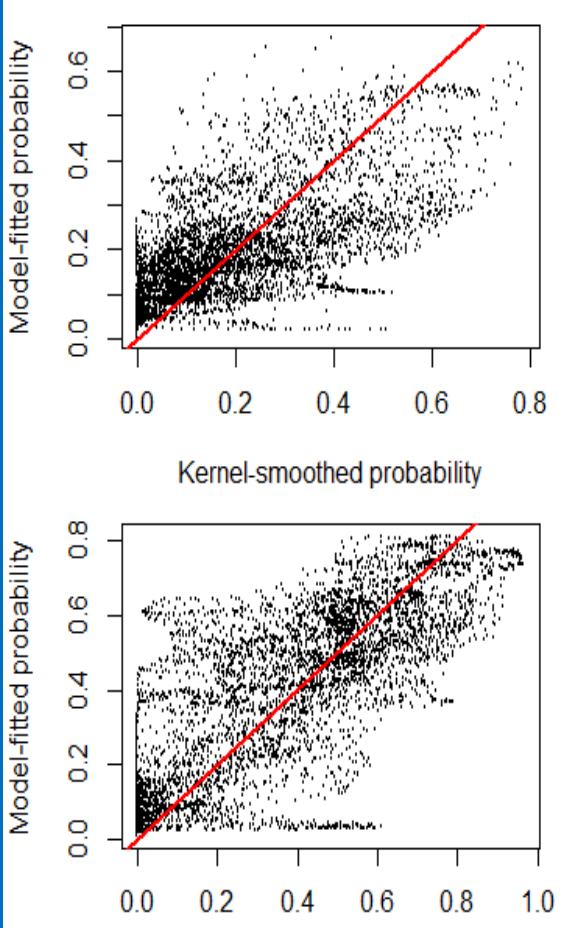

Kernel-smoothed probability

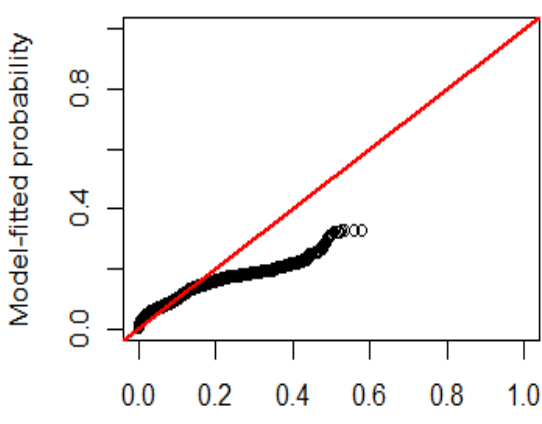

Kernel-smoothed probability

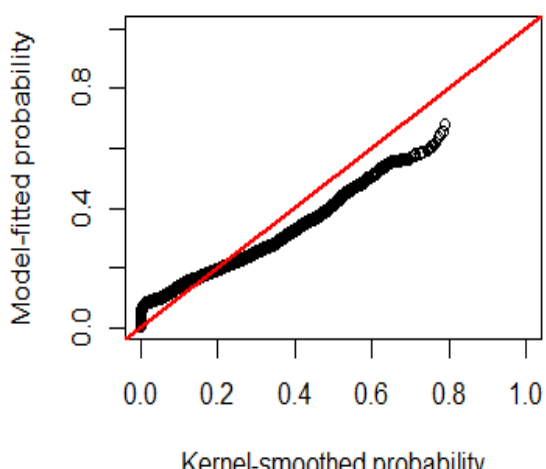

Kernel-smoothed probability

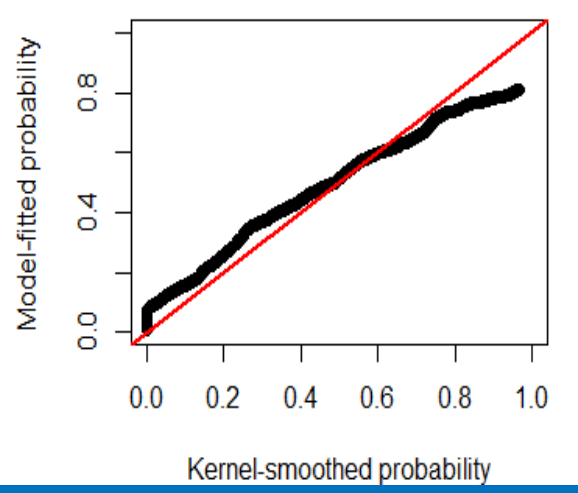




\section{Results: Model performances and diagnostics}

\section{The sub-model with overstory + understory filters}
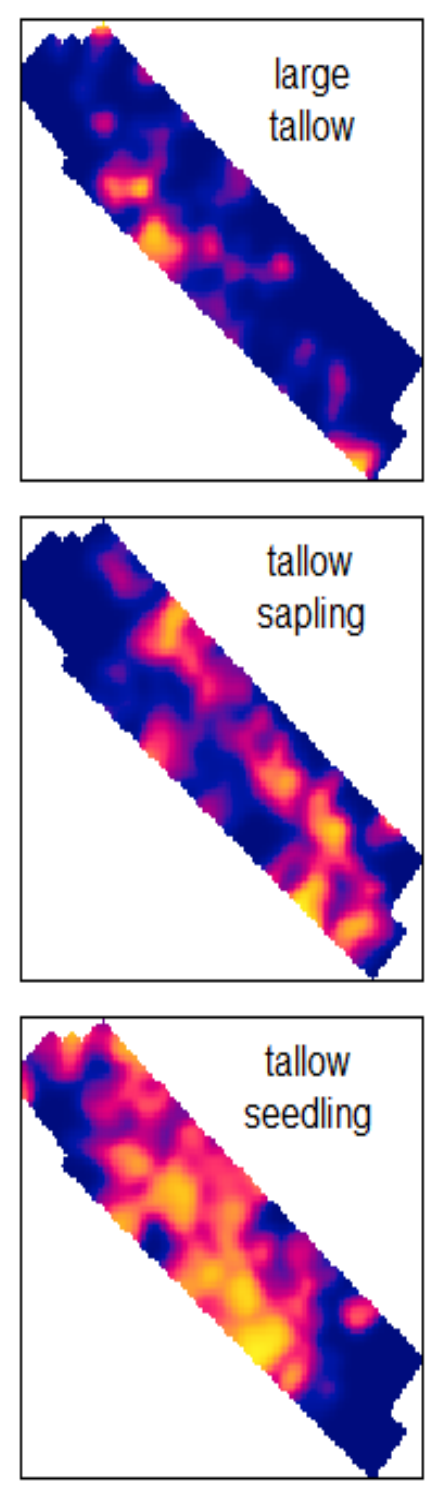
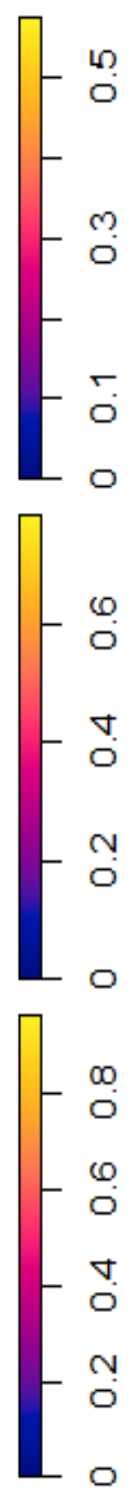
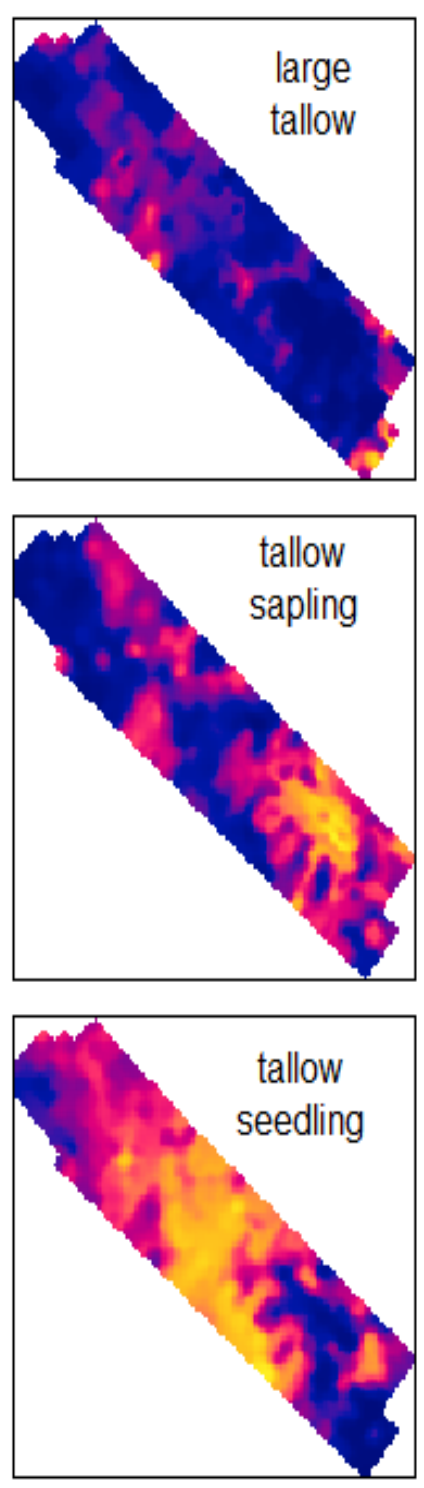
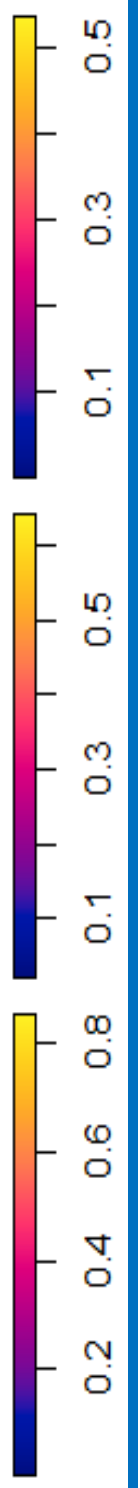

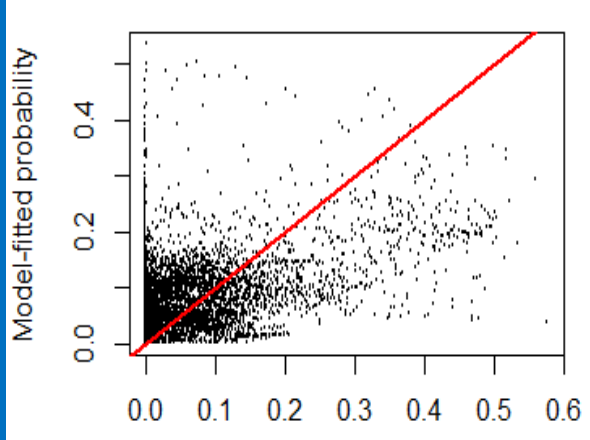

Kernel-smoothed probability

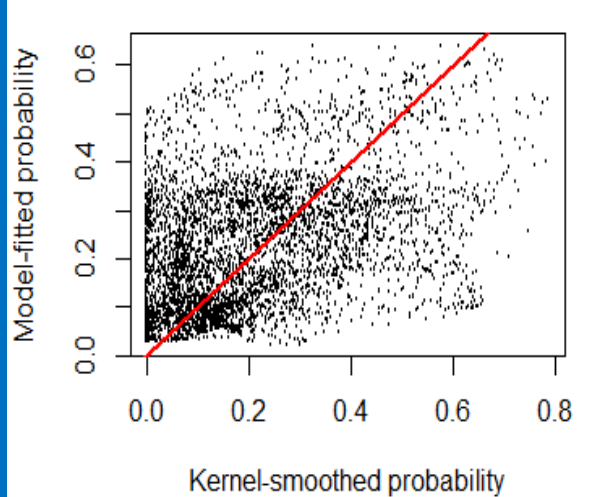

Kernel-smoothed probability

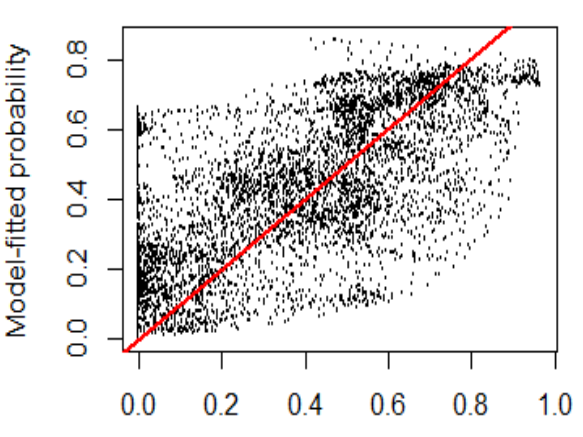

Kernel-smoothed probability

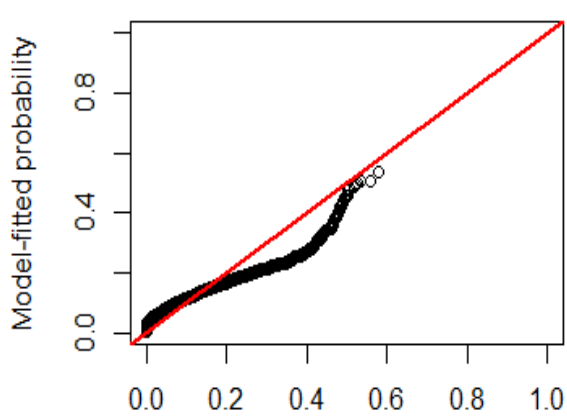

Kernel-smoothed probability

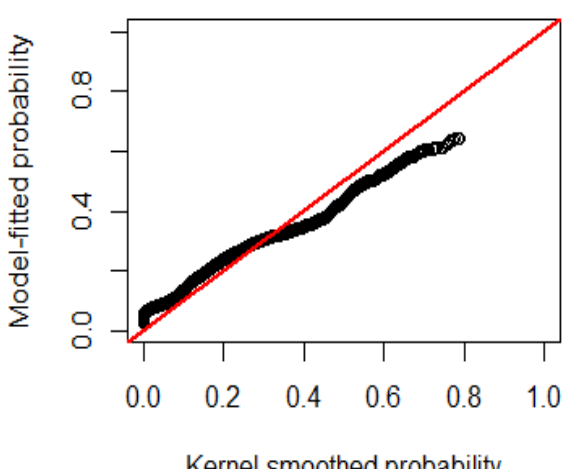

Kernel-smoothed probability

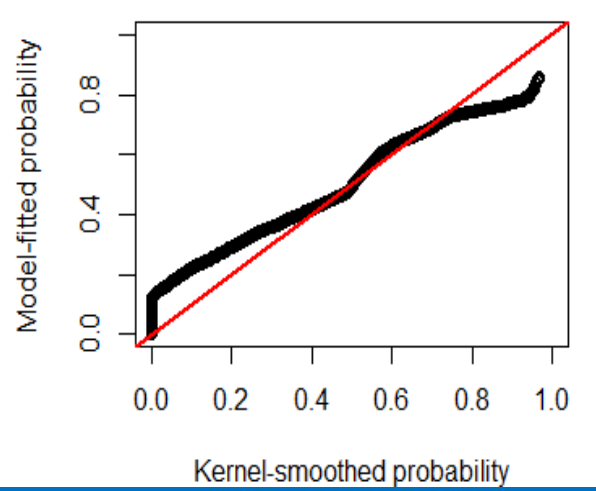


Results: Multitype point process models (full models and sub-models)

\begin{tabular}{|c|c|c|c|c|c|c|c|c|c|}
\hline Size classes & \multicolumn{3}{|c|}{ Large tallow trees } & \multicolumn{3}{|c|}{ Saplings } & \multicolumn{3}{|c|}{ Seedlings } \\
\hline Model types & $\mathrm{R}^{2}$ & Skewness & RSE & $R^{2}$ & Skewness & RSE & $\mathrm{R}^{2}$ & Skewness & RSE \\
\hline Full model $(D+O+U)$ & 0.464 & 1.611 & 0.071 & 0.498 & 0.467 & 0.123 & 0.637 & 0.262 & 0.160 \\
\hline Dispersal filters (D) & 0.172 & 2.020 & 0.088 & 0.420 & 0.587 & 0.133 & 0.634 & 0.059 & 0.161 \\
\hline Overstory filters (O) & 0.001 & 2.137 & 0.097 & 0.193 & 0.843 & 0.156 & 0.360 & 0.006 & 0.213 \\
\hline Understory filters (U) & 0.144 & 1.946 & 0.089 & 0.129 & 0.813 & 0.163 & 0.266 & -0.104 & 0.228 \\
\hline$D+O$ & 0.334 & 1.831 & 0.079 & 0.464 & 0.655 & 0.128 & 0.644 & 0.281 & 0.159 \\
\hline$D+U$ & 0.309 & 1.669 & 0.080 & 0.464 & 0.654 & 0.127 & 0.608 & 0.015 & 0.167 \\
\hline$O+U$ & 0.192 & 1.381 & 0.087 & 0.236 & 0.751 & 0.152 & 0.473 & -0.002 & 0.193 \\
\hline Full - grass cover & 0.384 & 1.618 & 0.076 & 0.508 & 0.569 & 0.122 & 0.635 & 0.178 & 0.161 \\
\hline Full - DEM & 0.471 & 1.608 & 0.070 & 0.430 & 0.435 & 0.131 & 0.653 & 0.318 & 0.157 \\
\hline $\begin{array}{l}\text { Full - pine: hardwood } \\
\text { ratio }\end{array}$ & 0.445 & 1.397 & 0.072 & 0.508 & 0.478 & 0.122 & 0.629 & 0.353 & 0.162 \\
\hline Full - canopy closure & 0.334 & 1.860 & 0.079 & 0.463 & 0.641 & 0.128 & 0.619 & -0.103 & 0.165 \\
\hline Full - seed sources & 0.269 & 1.359 & 0.083 & 0.333 & 0.561 & 0.142 & 0.462 & -0.028 & 0.196 \\
\hline Full - distance to road & 0.405 & 1.431 & 0.075 & 0.389 & 0.724 & 0.136 & 0.578 & 0.346 & 0.173 \\
\hline
\end{tabular}




\section{Summary}

1) Dispersal filters play a pivotal role for predicting spatial probability of tallow invasion.

2) None of the dispersal (D), overstory (O) and understory (U) filters are adequate for predicting spatial probability of tallow invasion. Either $\mathrm{D}+\mathrm{U}$ filters or $\mathrm{D}+\mathrm{U}$ filters will be needed to accurately predict spatial probability of tallow invasion.

3) The $O+U$ filters define the therotical invasibility of a community, but the D filters have to be included with the $O$ and/or $U$ filters to define the realized invasibility (observed invasion outcomes).

4) Management of tallow should first focus on quantifying the $D$ filters and then evaluating the $O$ and $U$ filters for invasion risk control in conserving slash pine flatwoods 


\section{Summary (Cont.)}

3) The role of fire in tallow invasion changes with invasion stages: short burn interval/time since last fire favors tallow seedling colonization and sapling establishment, but long burn interval favors large tallow tree development.

4) Overall, ecosystem invasibility can be quantified using multiple measures and by invasion stages, and the effect contributing factors be evaluated in a spatiallyexplicit context (landscape). 


\section{References}

Fan, Z., S. Yang, and X. Liu. 2018. Spatiotemporal patterns and mechanisms of Chinese tallowtree (Triadica sebifera) spread along edge habitat in a coastal landscape, Mississippi, USA. Invasive Plant Science and Management 11:117-126.

Fan, Z. 2018. Spatial analyses of invasion patterns of Chinese tallow (Triadica sebifera) in a wet slash pine (Pinus elliottii) flatwood in the coastal plain of Mississippi, USA. Forest Science $64,555-563$.

Yang S., Z. Fan, X. Liu, A. W. Ezell, M. A. Spetich, S. K. Saucier, S. Gray, and S. G. Hereford. 2019. Effects of prescribed fire, site factors, and seed sources on the spread of invasive Triadica sebifera in a fire-managed coastal landscape in southeastern Mississippi, USA. Forests. 10, 175; doi:10.3390/f10020175 


\section{Questions?}

